\title{
High ice water content at low radar reflectivity near deep convection - Part 2: Evaluation of microphysical pathways in updraft parcel simulations
}

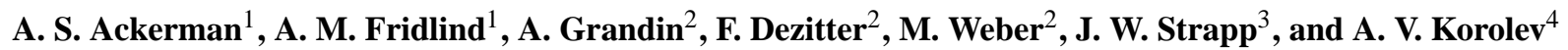 \\ ${ }^{1}$ NASA Goddard Institute for Space Studies, 2880 Broadway, New York, NY 10027, USA \\ ${ }^{2}$ Airbus Operations SAS, 316 route de Bayonne, 31060 Toulouse CEDEX 9, France \\ ${ }^{3}$ Met Analytics Inc., Aurora, Ontario, Canada \\ ${ }^{4}$ Cloud Physics and Severe Weather Research Section, Environment Canada, Toronto, Ontario, Canada
}

Correspondence to: A. S. Ackerman (andrew.ackerman@nasa.gov)

Received: 5 May 2015 - Published in Atmos. Chem. Phys. Discuss.: 17 June 2015

Revised: 4 October 2015 - Accepted: 12 October 2015 - Published: 22 October 2015

\begin{abstract}
The aeronautics industry has established that a threat to aircraft is posed by atmospheric conditions of substantial ice water content (IWC) where equivalent radar reflectivity $\left(Z_{\mathrm{e}}\right)$ does not exceed $20-30 \mathrm{dBZ}$ and supercooled water is not present; these conditions are encountered almost exclusively in the vicinity of deep convection. Part 1 (Fridlind et al., 2015) of this two-part study presents in situ measurements of such conditions sampled by Airbus in three tropical regions, commonly near $11 \mathrm{~km}$ and $-43^{\circ} \mathrm{C}$, and concludes that the measured ice particle size distributions are broadly consistent with past literature with profiling radar measurements of $Z_{\mathrm{e}}$ and mean Doppler velocity obtained within monsoonal deep convection in one of the regions sampled. In all three regions, the Airbus measurements generally indicate variable IWC that often exceeds $2 \mathrm{~g} \mathrm{~m}^{-3}$ with relatively uniform mass median area-equivalent diameter $\left(\mathrm{MMD}_{\mathrm{eq}}\right)$ of $200-300 \mu \mathrm{m}$. Here we use a parcel model with size-resolved microphysics to investigate microphysical pathways that could lead to such conditions. Our simulations indicate that homogeneous freezing of water drops produces a much smaller ice $\mathrm{MMD}_{\mathrm{eq}}$ than observed, and occurs only in the absence of hydrometeor gravitational collection for the conditions considered. Development of a mass mode of ice aloft that overlaps with the measurements requires a substantial source of small ice particles at temperatures of about $-10^{\circ} \mathrm{C}$ or warmer, which subsequently grow from water vapor. One conceivable source in our simulation framework is Hallett-Mossop ice production; another is abundant concentrations of heterogeneous ice freezing nuclei acting together
\end{abstract}

with copious shattering of water drops upon freezing. Regardless of the production mechanism, the dominant mass modal diameter of vapor-grown ice is reduced as the icemultiplication source strength increases and as competition for water vapor increases. Both mass and modal diameter are reduced by entrainment and by increasing aerosol concentrations. Weaker updrafts lead to greater mass and larger modal diameters of vapor-grown ice, the opposite of expectations regarding lofting of larger ice particles in stronger updrafts. While stronger updrafts do loft more dense ice particles produced primarily by raindrop freezing, we find that weaker updrafts allow the warm rain process to reduce competition for diffusional growth of the less dense ice expected to persist in convective outflow.

\section{Introduction}

Over the last 25 years, more than 160 incidents of jet engine power loss have been traced to flight through fully glaciated clouds under conditions that can cause engine rollback events (uncommanded power loss), engine flameouts, and engine damage (Mason and Grzych, 2011; Bravin et al., 2015). Crew reports consistently include the following conditions (Lawson et al., 1998; Grzych and Mason, 2010; Mason and Grzych, 2011): (1) lack of significant airframe icing, (2) low to moderate turbulence, (3) anomalous true air temperature readings owing to probe inlet icing, (4) flight level radar equivalent reflectivity $\left(Z_{\mathrm{e}}\right)$ below $20-30 \mathrm{dBZ}$, and 
(5) moderate to heavy rain below the melting level indicated by $Z_{\mathrm{e}}$ greater than $30 \mathrm{dBZ}$. The aeronautics industry concluded that unexpectedly high ice water content (IWC) at relatively low $Z_{\mathrm{e}}$ is most likely responsible (Mason et al., 2006). The event conditions are described in greater detail in Sect. 2 of Fridlind et al. (2015, hereafter Part 1).

We hereafter refer to the principle meteorological signature of the jet engine power loss events as "high IWC-low $Z_{\mathrm{e}}$ " conditions. Here, the definition of low $Z_{\mathrm{e}}$ is less than $20 \mathrm{dBZ}$, roughly the minimum reflectivity seen on aircraft radar using the baseline gain setting. The definition of high IWC, on the other hand, is not well known. Hot-wire probes have been found to fail or perform erratically under field conditions found sufficient to induce rollback in a flight test (Strapp et al., 1999). Indirect means of measuring IWC by integrating measured ice particle size distribution are typically subject to uncertainties that may be a factor of 2 or more (e.g., McFarquhar and Heymsfield, 1996). Instrument development in general suffers from a lack of sufficiently calibrated testing conditions, such as in wind tunnels (e.g., Strapp et al., 2008; Lawson et al., 2010; Baumgardner et al., 2011).

To better characterize high IWC-low $Z_{\mathrm{e}}$ conditions, Airbus conducted a series of flight tests from Cayenne, Darwin, and Santiago during 2010-2012 (Grandin et al., 2014). In each location, an Airbus 340 was flown with an imaging nephelometer (Roques, 2007) and the Robust hot-wire probe designed by Science Engineering Associates (SEA) and tested under wind tunnel conditions up to IWC of about $8 \mathrm{~g} \mathrm{~m}^{-3}$ (see discussion in Sect. 3 of Part 1). Flight tests sought to sample large, cold-topped mesoscale convective systems (MCSs), where more than $80 \%$ of documented events have occurred (Mason and Grzych, 2011). In Sect. 3 of Part 1, we present a survey of the Airbus measurements and an analysis of the highest IWC conditions encountered in all three regions at cruise altitudes around $10-12 \mathrm{~km}$ and -40 to $-50{ }^{\circ} \mathrm{C}$. These cold temperatures were the focus of the Airbus flight tests, in part because over one-third of the engine events reported by Grzych and Mason (2010) occurred at temperatures colder than $-35^{\circ} \mathrm{C}$ (and over a quarter at temperatures colder than $-40^{\circ} \mathrm{C}$ ). The importance of such cold temperatures is further supported by the latest Boeing engine icing event database of 162 events occurring at a median temperature of $-36^{\circ} \mathrm{C}$ (Bravin et al., 2015). IWC derived from the Robust probe measurements and integration of the nephelometer size distributions generally agree to about $25 \%$ over a wide range of IWC; uncertainty in each is estimated to be roughly a factor of 2 owing in large part to the uncertainty in Robust probe calibration (Grandin et al., 2014) and in the mass-dimensional relationship applied to the nephelometer size distribution measurements (Heymsfield and McFarquhar, 1996). At each location, reported IWC exceeded $2-4 \mathrm{~g} \mathrm{~m}^{-3}$ during multiple flights. Under the conditions of highest IWC in all regions, measured ice size distributions exhibited a concentration of mass within the size range $100-500 \mu \mathrm{m}$ in area-equivalent diameter $\left(D_{\text {eq }}\right.$; the diameter of a circle with the same area), with corresponding mass median area-equivalent diameter $\left(\mathrm{MMD}_{\mathrm{eq}}\right)$ of 200 $300 \mu \mathrm{m}$; uncertainty in $\mathrm{MMD}_{\mathrm{eq}}$ is estimated to be roughly $20 \%$ owing in large part to uncertainty in shattering artifacts that may contaminate airborne particle probe measurements in a manner that decreases as the moment of the size distribution increases (Korolev et al., 2013; Jackson and McFarquhar, 2014).

Owing to the substantial uncertainty associated with both IWC and ice size distribution from in situ measurements (Strapp et al., 2008; Baumgardner et al., 2011), Sect. 4 of Part 1 of this work assesses the consistency of the Airbus data with remote-sensing measurements of a large MCS observed over Darwin, Australia, on 23 January 2006 during the Tropical Warm Pool International Cloud Experiment (TWP-ICE) (May et al., 2008).

To briefly summarize the results in Part 1 , a survey of the Airbus data found relatively narrow ice mass size distributions spanning $D_{\text {eq }}$ of $100-500 \mu \mathrm{m}$ with $\mathrm{MMD}_{\text {eq }}$ of 200 $300 \mu \mathrm{m}$ associated with the highest IWC conditions measured in all three regions, and these features appear consistent with remote-sensing measurements from TWP-ICE and in situ measurements reported elsewhere, thus motivating the effort here in Part 2 to investigate microphysical pathways that could lead to such size distributions. Given the fundamental, open questions about the dominant microphysical processes for varying updraft conditions, here we use an idealized parcel modeling framework. In the following we first briefly summarize relevant deep convection updraft properties in Sect. 2 and earlier results from CRM simulations in Sect. 3. We then describe the parcel model and simulations in Sect. 4, comparing results with the Airbus measurements throughout. After a discussion in Sect. 5, we summarize our findings in Sect. 6.

\section{Updraft microphysical pathways}

A prominent feature of the Airbus measurements used here is the consistent concentration of mass among particles with $D_{\text {eq }}$ of $100-500 \mu \mathrm{m}$. Upon finding anvil and also turret mass size distributions similarly dominated by particles with maximum dimensions of a few hundred micrometers over Central America and western Africa, Lawson et al. (2010) hypothesized that this size distribution signature pointed to a particular series of microphysical processes: heterogeneous freezing of raindrops at temperatures warmer than $-10^{\circ} \mathrm{C}$ leading to graupel that would preferentially sediment; heterogeneous freezing of remaining water drops at temperatures colder than $-12{ }^{\circ} \mathrm{C}$ leading to vapor-grown crystals of several hundred micrometers in size and their aggregates; and possibly homogeneous freezing of any droplets remaining at $-40^{\circ} \mathrm{C}$, which would preferentially sublimate upon outflow. Lawson et al. (2010) also discussed two classes of larger par- 
ticles: graupel particles formed by riming within updrafts, which sediment within or near to their sources, and aggregates formed by collisions of non-graupel ice both within updrafts and after detrainment, which preferentially occupy lower anvil regions, consistent with past findings (e.g., McFarquhar and Heymsfield, 1996).

A key aspect of the Lawson et al. (2010) conceptual model is that particles dominating anvil mass originate as similarly sized particles from updraft turrets. In addition, they are identified as vapor-grown or only lightly rimed particles. This identification appears consistent with the common presence of capped columns in the Airbus measurements (Fig. 1), a habit found elsewhere in tropical deep convection outflow (cf. Heymsfield et al., 2002; Lawson et al., 2010). The majority of crystals in the Airbus measurements appear irregular and are generally of insufficient clarity to distinguish rime or other morphological details. The Lawson et al. (2010) attribution of mass-dominating ice to freezing of water drops by heterogeneous nuclei is consistent with Cziczo et al. (2013), who reported cirrus ice residuals being predominantly of mineral or metallic composition in deep convection outflow and synoptic cirrus. To explain compositional dissimilarity between the population of near-cloud aerosols and ice residuals, Cziczo et al. (2013) argued for the predominance of heterogeneous freezing, as discussed further below.

In motivating a satellite-based analysis of convective cloud-top phase, Rosenfeld et al. (2011) pointed to "wide gaps in our understanding of the processes that glaciate clouds". In motivating an aerosol-focused comparison of deep convection simulations with observations, Connolly et al. (2012) reported "very few studies that verify their results against observations" in the modeling literature. Evidence of a gap in knowledge of primary microphysical pathways within deep convection updrafts can also be found in the broad range of ice conditions simulated within tropical deep convection by various microphysics schemes (e.g., Zhu et al., 2012). Observational studies commonly refer to posited updraft microphysical pathways as hypothetical in nature, for instance in considering volcanic aerosol effects on electrification within maritime updrafts (Yuan et al., 2011) or the dependence of deep convection properties on aerosol in general (Rosenfeld et al., 2008). The role of primary ice nucleation is also debated, with some studies suggesting little role for heterogeneous freezing in deep convection (e.g., Khain et al., 2008), and others suggesting an important role for heterogeneous freezing in determining the updraft glaciation rate (e.g., Rosenfeld et al., 2011). Other processes suggested to play prominent roles in updraft glaciation include the Hallett-Mossop rime-splintering process (e.g., Blyth and Latham, 1997) and drop shattering during freezing (e.g., Rangno and Hobbs, 2005), among others; see also Fridlind et al. (2007) and references therein.

In this study we turn to the rudimentary tool of parcel simulation to investigate pathways that can explain the Airbus ice measurements, given that more expensive and com-

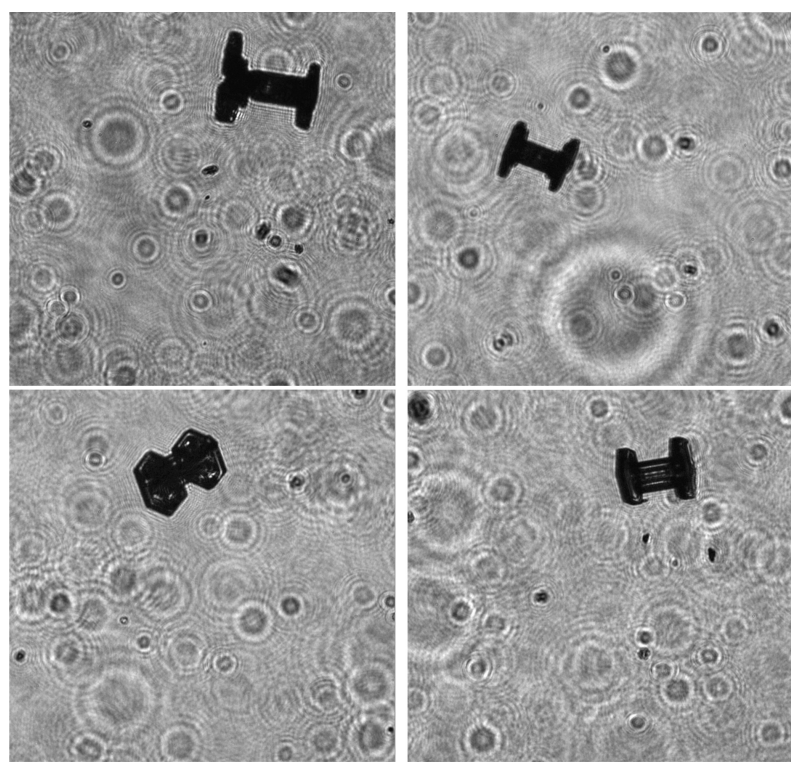

Figure 1. Imaging nephelometer views of capped columns from Airbus flight tests. Images are $512 \times 512$ square pixels $3 \mu \mathrm{m}$ in width, for a total image size of about $1.5 \mathrm{~mm} \times 1.5 \mathrm{~mm}$. Maximum dimensions of these capped columns are about $300 \mu \mathrm{m}$.

plex simulations suffer from relatively gross deficiencies (described below), which could well stem from missing or poorly represented ice formation processes.

\section{CRM simulations}

IWC and $Z_{\mathrm{e}}$ from three 3-D cloud-resolving model (CRM) simulations of the 23 January MCS during TWP-ICE are shown in Fig. 2. The first two simulations - System for Atmospheric Modeling (SAM)-2M, Distributed Hydrodynamic Aerosol and Radiative Modeling for Atmospheres (DHARMA)-2M - both using two-moment bulk microphysics and sampled every $3 \mathrm{~h}$, are typical of CRM simulations reported in a model intercomparison that included the 23 January period examined in Sects. 4-6 of Part 1 of this study (Fridlind et al., 2012; Varble et al., 2015). The CRM simulations did not generally differ systematically from limited-area model simulations (Zhu et al., 2012; Varble et al., 2015). At temperatures in a $10^{\circ}$ range around $-40^{\circ} \mathrm{C}$, statistics from SAM-2M and DHARMA-2M fields during the MCS period (12:00-24:00 UTC) contain regions of 2$4 \mathrm{~g} \mathrm{~m}^{-3}$ IWC, but these are rare where $Z_{\mathrm{e}}<30 \mathrm{dBZ}$ (area delimited by dashed line in the figure) and non-existent where $Z_{\mathrm{e}}<20 \mathrm{dBZ}$. Because the ice size distributions are assumed to be exponential, reflectivity may be unrealistically high. However, Varble et al. (2015) also concluded that these simulations, like the others they examined, exhibited stratiform rain rates notably lower than observed, which they attributed primarily to insufficient IWC aloft rather than other factors. 

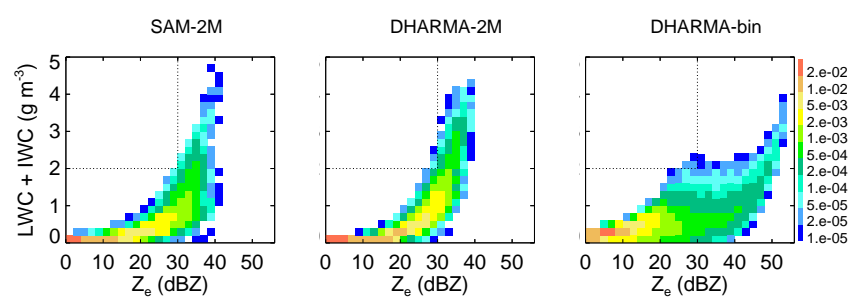

Figure 2. Joint histograms of Rayleigh-regime equivalent radar reflectivity $Z_{\mathrm{e}}$ vs. total hydrometeor condensed water content LWC + IWC from the last $12 \mathrm{~h}$ of 23 January TWP-ICE simulations using the System for Atmospheric Modeling (SAM) with two-moment microphysics (left panel) and the Distributed Hydrodynamic Aerosol and Radiative Modeling for Atmospheres (DHARMA) using two-moment and bin microphysics (center and right panels, respectively) at an altitude where the mean air temperature is $-40^{\circ} \mathrm{C}$.

The third simulation, using bin microphysics (DHARMAbin) on a domain with a quarter of the horizontal area and restarted from the DHARMA-2M simulation at 03:00 UTC on 23 January (van Diedenhoven et al., 2012), does not assume any size distribution shape for hydrometeors, but IWC greater than $2 \mathrm{~g} \mathrm{~m}^{-3}$ is still similarly absent at $Z_{\mathrm{e}}$ less than $20 \mathrm{dBZ}$, for instance. By contrast, such conditions were repeatedly found in Airbus measurements and also appear consistent with remote-sensing measurements of the 23 January event, as described in Sects. 4-6 of Part 1.

Figure 3 compares ice size distributions from the DHARMA-bin simulation with those measured during Airbus flight 1423, which are typical of those found in Airbus measurements where the greatest IWC was typically found at an altitude of $10-12 \mathrm{~km}$ (see Sect. 3 of Part 1). While the simulation and measurements both reveal consistent modal features across a wide range of IWC, the majority of mass in the measurements is concentrated at $D_{\text {eq }} \sim 100-500 \mu \mathrm{m}$. In the simulations, the highest IWC is found in the presence of graupel within convective cores, which constitutes the primary mass-containing mode at $1000 \mu \mathrm{m}$. Where no such graupel is present, in the quiescent anvil regions, ice mass spans $100-1000 \mu \mathrm{m}$ and is present at IWC much lesser than observed. Thus, in areas with similarly sized ice in the simulation, the simulated mode is notably wider than observed and contains far less mass. We note that the larger particle size mode in the simulations is located in convective cores, whereas the Airbus flight tests only skirted convective cores for the sake of flight safety and the ice particles comprising most of the mass are not graupel.

Although not exhaustive, from these comparisons we conclude that detailed CRM simulations of tropical MCS conditions do not consistently produce high IWC-low $Z_{\mathrm{e}}$ conditions insofar as "high IWC" is interpreted as exceeding $2 \mathrm{~g} \mathrm{~m}^{-3}$. Given the many outstanding questions about the dominant microphysical processes determining deep convection updraft glaciation rates and ice outflow properties, to-
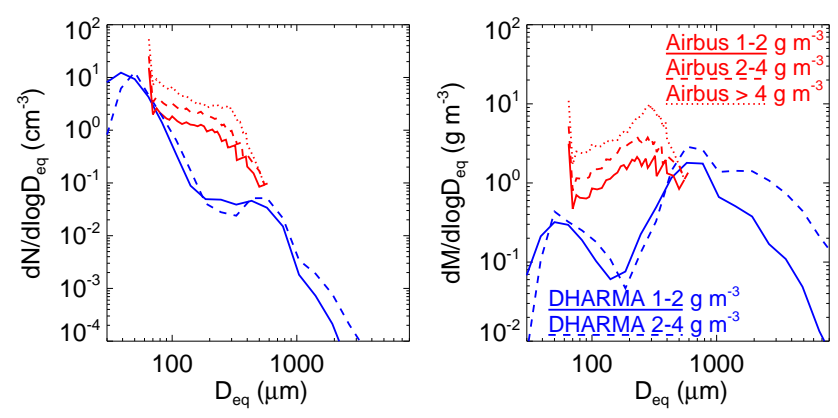

Figure 3. Particle size distributions in terms of number $(N$, left $)$ and mass $(M$, right) as functions of area-equivalent particle diameter ( $\left.D_{\text {eq }}\right)$ obtained during Airbus flight test out of Cayenne (red lines) and from DHARMA-bin simulations (as in Fig. 2; blue lines). Different line patterns correspond to IWC ranges as indicated. Airbus measurements encompass flight 1423, as discussed at length and shown in Figs. 4-6 of Part 1. DHARMA-bin results are from a horizontal line spanning the $88 \mathrm{~km}$ wide domain through the point of maximum IWC at $11.7 \mathrm{~km}\left(-43.7^{\circ} \mathrm{C}\right)$ at $21: 40$ UTC on 23 January 2006 , typical of mature convection in the simulation.

gether with the corresponding computational expense and complexity of investigating possible reasons for deficiencies in CRM simulations, here we consider idealized parcel simulations.

\section{Parcel simulations}

In Sects. 4.1 and 4.2 we describe the components and setup of the minimal parcel model, which omits all processes not described therein. Section 4.3 presents results from the minimal model, followed by a series of sections in which a process or family of associated processes is sequentially added in each: heterogeneous ice freezing (Sect. 4.4), Hallett-Mossop ice production (Sect. 4.5), particle sedimentation (Sect. 4.6), gravitational collection and raindrop breakup, excluding iceice collisions (Sect. 4.7), ice-ice collisions (Sect. 4.8), shattering of freezing drops (Sect. 4.9), and entrainment of environmental air (Sect. 4.10). We finish Sect. 4 by considering sensitivity of the results to ice properties (Sect. 4.11), aerosol population (Sect. 4.12), and cloud-base altitude (Sect. 4.13).

\subsection{Baseline model description}

We begin with a parcel model that uses the Community Aerosol-Radiation-Microphysics for Atmospheres (CARMA) code (Ackerman et al., 1995; Jensen et al., 1998) to resolve particle size distributions (PSDs) without any assumptions regarding PSD shape for three particle classes: unactivated aerosol, water drops, and pristine ice particles. The prognostic variables in the model are potential temperature, water vapor mixing ratio, and the number concentration of particles within a uniform number of size bins for each of the three particle classes. For hydrometeors the mass con- 
centration of aerosol within each size bin is also prognostic. The size bins correspond to a geometric progression of total particle mass and the number of bins in the model is flexible. The mass bins for ice particles are matched to those for water drops, and thus changes to the assumed mass-dimensional relation, which do not change during a simulation, result in changes to the corresponding ice particle densities and sizes. All simulations include adiabatic expansion, droplet activation, diffusional growth of hydrometeors, and homogeneous freezing of activated water drops.

The vertical profile of updraft speed $w$ is specified as a function of height $z$ above the surface, and the height of the parcel is incremented by $\Delta z=w \Delta t$ each time step of duration $\Delta t$. Parcel expansion is treated by assuming dry adiabatic ascent and iterating 3 times on parcel air pressure, temperature, and density assuming hydrostatic conditions and using the ideal gas law. All prognostic particle concentrations are then rescaled by the new air density. Latent heat released by water phase change is applied to the air temperature of the parcel using the time step for the process involved (described in next section).

Uptake of water by unactivated aerosol is neglected and activation of aerosol particles to water droplets is computed following Ackerman et al. (1995). Diffusional growth of hydrometeors from water vapor is treated with the piecewise polynomial method of Colella and Woodward (1984) where the Courant-Friedrichs-Lewy condition is met on the mass grid, and first-order upwind advection elsewhere. Growth rates for water drops are computed from Eq. (3) of Ackerman et al. (1995) for water drops, and for ice particles the capacitance method described in Sect. 13.3 of Pruppacher and Klett (1997) is used assuming spheroids. The accommodation coefficient for diffusional growth is assumed to be unity. Radiative heating effects on activation and growth rates are neglected. Homogeneous freezing of water drops is computed following Pruppacher and Klett (1997).

\subsection{Setup}

For parcel simulations that omit gravitational collection we include only one ice class, representing vapor-grown ice particles. For the baseline model configuration, we treat the ice as low-density spheres in which the density is computed from the mass-dimensional relation that Locatelli and Hobbs (1974) found for aggregates of unrimed radiating assemblages of plates, side planes, bullets, and columns. Like Brown and Francis (1995), we apply this mass-dimensional relation to ice particles smaller than the $1 \mathrm{~mm}$ lower limit of Locatelli and Hobbs (1974), but unlike Brown and Francis (1995) we use the diameter of a sphere with equivalent cross sectional area as done by Locatelli and Hobbs (1974) and as used in the analysis of Airbus nephelometer data. For area-equivalent diameters $D_{\text {eq }}$ less than about $100 \mu \mathrm{m}$ this relation implies an ice particle density exceeding that of bulk ice; for those sizes we assume spherical ice particles with
Table 1. Parameters for three lognormal modes of initial aerosol size distribution. For each mode, $N$ is total number concentration, $r_{\mathrm{g}}$ mean geometric radius, and $\sigma_{\mathrm{g}}$ mean geometric standard deviation.

\begin{tabular}{lrr}
\hline$N$ & $\begin{array}{r}r_{\mathrm{g}} \\
\mathrm{cm}^{-3}\end{array}$ & $\begin{array}{r}\sigma_{\mathrm{g}} \\
-\end{array}$ \\
\hline 447 & 0.015 & 1.12 \\
26 & 0.09 & 1.45 \\
1.6 & 2.2 & 1.8 \\
\hline
\end{tabular}

a fixed density of $0.92 \mathrm{~g} \mathrm{~cm}^{-3}$ (Pruppacher and Klett, 1997). We simplistically refer to these vapor-grown ice particles as "fluffy" ice.

Here, we use 150 size bins corresponding to spherical diameter for aerosol particles ranging from $10 \mathrm{~nm}$ to $14 \mu \mathrm{m}$ and for water drops from $2 \mu \mathrm{m}$ to $6.5 \mathrm{~mm}$.

The aerosol are treated as ammonium bisulfate with properties as given by Ackerman et al. (1995). For the initial aerosol size distribution (see Table 1), we use the trimodal lognormal fit to TWP-ICE measurements at $500 \mathrm{~m}$ altitude from Fridlind et al. (2012).

All processes are computed on the master time step of $\Delta t=1 \mathrm{~s}$ with the exception of droplet activation, droplet homogeneous freezing, and hydrometeor diffusional growth, which are solved on $0.1 \mathrm{~s}$ sub-steps. Parameters that depend on pressure and temperature are updated every $15 \mathrm{~s}$. Such parameters include particle terminal fall speeds, the gravitational collection kernel, and coefficients for droplet activation and hydrometeor diffusional growth.

The parcel simulations start at $500 \mathrm{~m}$ altitude with initial conditions from the 21:00 UTC TWP-ICE sounding on 23 January 2006 (Fridlind et al., 2012) with air pressure at $944 \mathrm{hPa}$, temperature $296.8 \mathrm{~K}$, and relative humidity $98 \%$.

For the assumed vertical profile of updraft speed, seen in upper left panel of Fig. 4, we use a coarse spline fit to the Varble et al. (2014) median profile of maximum retrieved updraft speeds during a period of about $4.5 \mathrm{~h}$ as a large monsoonal MCS passed over Darwin during TWP-ICE. For the baseline profile the updraft speed rapidly increases to about $8 \mathrm{~m} \mathrm{~s}^{-1}$ at $4 \mathrm{~km}$, increases at a reduced rate to about $11 \mathrm{~m} \mathrm{~s}^{-1}$ just above $10 \mathrm{~km}$, and falls off at an intermediate rate above, reaching $6 \mathrm{~m} \mathrm{~s}^{-1}$ at $15 \mathrm{~km}$, which lies above the highest levels we consider here; for the spline fit we use updraft speeds of $0,7,11$, and $0 \mathrm{~m} \mathrm{~s}^{-1}$ at respective altitudes of $0,3,11$, and $18 \mathrm{~km}$. This profile resembles the mean profile of maximum updraft speeds in oceanic deep convection from the airborne Doppler retrievals of Heymsfield et al. (2010), with values in the median profile here generally about $2 \mathrm{~m} \mathrm{~s}^{-1}$ less than in that mean profile. For many scenarios we consider two alternative updraft profiles, uniformly increasing and decreasing baseline updraft speeds by $50 \%$, as seen in Fig. 4 . The time 

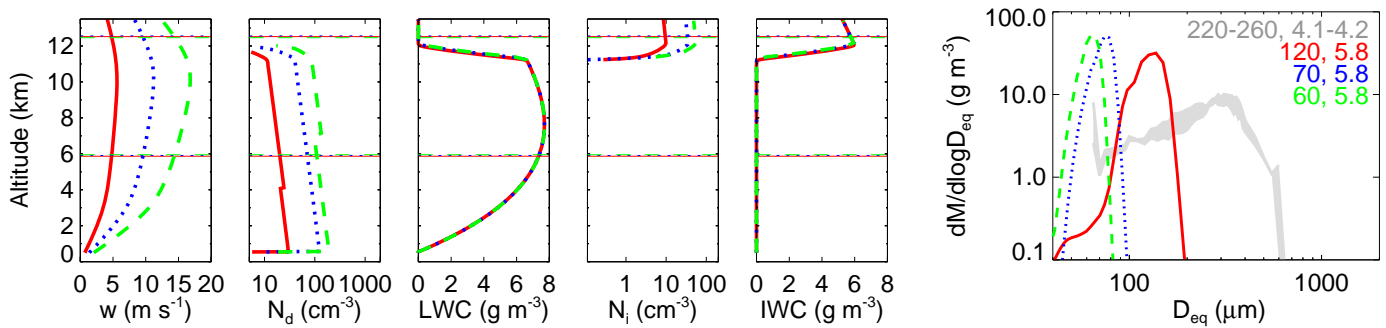

Figure 4. Profiles of parcel updraft speed $(w)$, water drop concentration $\left(N_{\mathrm{d}}\right)$, liquid water content (LWC), ice particle concentration $\left(N_{\mathrm{i}}\right)$, and ice water content (IWC), and ice particle size distribution (PSD) at output level nearest $-40{ }^{\circ} \mathrm{C}$ for simulations with droplet activation, diffusional growth, and homogeneous drop freezing only, and baseline updraft strength scaled by factors of 0.5 (red solid line), 1.0 (blue dotted line), and 1.5 (green dashed line), Shaded area in PSD panel is envelope of median Airbus PSDs from Cayenne and Darwin for IWC $>4 \mathrm{~g} \mathrm{~m}^{-3}$ (see Fig. 6 of Part 1). Horizontal lines in profiles correspond to 0 and $-40^{\circ} \mathrm{C}$. PSD is plotted in terms of ice particle mass $(M)$ and area-equivalent diameter $D_{\text {eq }}$. The numbers in the upper right of the PSD panel are MMDeq in units of $\mu \mathrm{m}$ and IWC in units of

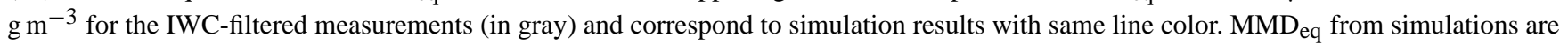
rounded to nearest $5 \mu \mathrm{m}$ to reduce attention to smaller differences attributable to variations in height resulting from $10 \mathrm{~s}$ output frequency.

for a parcel to ascend from cloud base to $-40^{\circ} \mathrm{C}$ is just over $25 \mathrm{~min}$ for the baseline updraft.

\subsection{Homogeneous freezing}

First we consider only adiabatic expansion, droplet activation, diffusional growth, and homogeneous freezing of water drops. As seen in Fig. 4, stronger updrafts activate more aerosol by driving a greater supersaturations near cloud base (not shown), which drives greater number concentrations of ice upon homogeneous freezing of the water drops between about -35 and $-36^{\circ} \mathrm{C}$. Since the liquid water content (LWC) that freezes does not vary with updraft strength, the freezing of more numerous droplets in the faster updrafts simply produces smaller ice particles. It is seen in the comparison of ice particle mass distributions that homogeneous freezing produces substantially smaller ice particles and greater IWC than in the Airbus measurements. For the baseline and strong updraft, the PSDs overlap with the hint of an upturn in the Airbus PSD envelope at the small end of the PSD measurements, suggesting that this smaller mode, if real and not a shattering artifact, could correspond to homogeneously frozen water drops, which would be expected to be more favored in stronger updrafts. As noted above, there is observational evidence for homogeneous freezing in strong updrafts (e.g., Khain et al., 2012; Gayet et al., 2014; Stith et al., 2014). In these simplified simulations, the size of homogeneously frozen drops best matches observations for the strong updraft.

Discontinuities are seen in the profiles of droplet number concentration in Fig. 4 and in later profiles. Such discontinuities result from discretization of the aerosol size distribution and treatment of activation of droplets from aerosol by size bin as a nearly instantaneous process. Solutions to reduce such an artifact could be devised, but we lack evidence that this artifact materially affects results or conclusions here.

\subsection{Heterogeneous freezing}

Our treatment of heterogeneous ice freezing nuclei (IFN) considers freezing of activated water drops in the immersion and condensation modes using the approach described by Fridlind et al. (2007). IFN activation follows the temperaturedependent fit provided in Fig. 2 of DeMott et al. (2010), without extrapolating beyond their sampled temperature range of -9 to $-35^{\circ} \mathrm{C}$. The IFN are treated prognostically, assumed equally distributed among unactivated aerosol and droplets, and consumed when activated. Adding such IFN has a negligible impact on our results even when the total number available is tenfold that of the DeMott et al. (2010) fit. Only when the concentration is increased by a factor of 100 do the IFN affect the results, with a very weak second mode developing at larger sizes as seen in Fig. 5, with $D_{\text {eq }} \sim 200 \mu \mathrm{m}$. This factor of 100 corresponds to an IFN concentration of $1 \mathrm{std} \mathrm{cm}^{-3}$ at $-35^{\circ} \mathrm{C}$, which is about 5 times greater than the greatest measured value contributing to the fit reported by DeMott et al. (2010). At warmer temperatures the factor of 100 provides modest numbers of IFN, corresponding to about $0.04 \mathrm{std} \mathrm{cm}^{-3}$ at $-10^{\circ} \mathrm{C}$.

\subsection{Hallett-Mossop ice production}

Given the mild response to even a hundredfold increase in IFN active in the immersion mode relative to measured IFN concentrations, we next consider a source of ice particles effective at much warmer temperatures: ice multiplication from production of ice splinters associated with riming of supercooled water (Hallett and Mossop, 1974). Lacking a source of graupel entering the parcel from above, we crudely represent the Hallett-Mossop process with a "pseudo" version in which ice particles are introduced in the smallest size bin between temperatures of -3 and $-8^{\circ} \mathrm{C}$ and the water drop PSD rescaled to conserve total moisture. The potential ice embryos are treated prognostically and consumed when ac- 

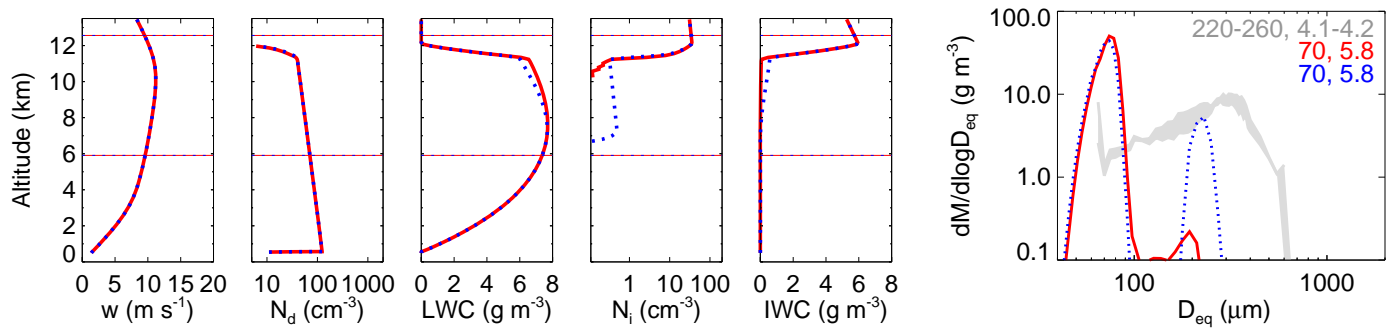

Figure 5. As in Fig. 4 for simulations that also include $1 \mathrm{std} \mathrm{cm}^{-3}$ of immersion-mode IFN (red solid line) or pseudo-Hallett-Mossop embryos (blue dotted line), both with baseline updraft. Details provided in text.

tivated. The temperature dependence of their availability follows the triangular form of Eqs. (16)-(71) of Pruppacher and Klett (1997) and peaks at $-5^{\circ} \mathrm{C}$.

Hallett and Mossop (1974) measured production of about 350 splinters per milligram of rime accreted by graupel at $-5^{\circ} \mathrm{C}$ (see also Pruppacher and Klett, 1997). The parcel air density at $-5^{\circ} \mathrm{C}$ is about $0.6 \mathrm{~kg} \mathrm{~m}^{-3}$, where a concentration of $1 \mathrm{std} \mathrm{cm}^{-3}$ is equivalent to about $0.5 \mathrm{~cm}^{-3}$. Thus, $1 \mathrm{std} \mathrm{cm}^{-3}$ of splinters would require about $1.4 \mathrm{~g} \mathrm{~m}^{-3}$ of accreted rime, or roughly $20 \%$ of the supercooled water available in the parcel at that temperature. On the basis of laboratory measurements (Mossop and Hallet, 1974; Mossop, 1976), Pruppacher and Klett (1997, p. 358) also note that approximately one splinter is produced for every 100 to 250 water drops larger than $24 \mu \mathrm{m}$ diameter accreted by graupel at $-5^{\circ} \mathrm{C}$, and thus $0.5 \mathrm{~cm}^{-3}\left(\sim 1 \mathrm{std} \mathrm{cm}^{-3}\right)$ of splinters would require 50 to $125 \mathrm{~cm}^{-3}$ of such drops. At levels corresponding to the Hallett-Mossop temperature range, effectively all drops are larger than $24 \mu \mathrm{m}$ in diameter, and the required drop number concentrations $\left(N_{\mathrm{d}}\right)$ exceed $N_{\mathrm{d}}$ at that level for the slow updraft, and bracket $N_{\mathrm{d}}$ for the baseline and strong updrafts. However, our crude representation of splinter production does not consume drops as real riming would, and a substantial sink of drops can readily drive supersaturations that activate new drops (as seen in a number of simulations below), which might provide sufficient numbers of additional drops if riming were represented more physically, as well as providing a supply of droplets smaller than $13 \mu \mathrm{m}$ diameter that are also required for ice production from rime splintering (Pruppacher and Klett, 1997, p. 358).

As seen in Fig. 5 formation of copious ice at such warm temperatures provides ample time for diffusional growth, and the resulting second mode is far more substantial than that produced by IFN alone, and is comprised of somewhat larger particles closer to the observational target. At temperatures colder than homogeneous drop freezing, however, the mass and numbers of ice particles are still dominated by homogeneously frozen drops, and their $\mathrm{MMD}_{\mathrm{eq}}$ is unaffected.

The implication that the dominant mode of mass in the Airbus size distributions results from ice particles that form at relatively warm temperatures and are largely vaporgrown is consistent with the common appearance of capped columns in the Airbus particle imagery presented in Fig. 1. Such a habit is consistent with the formation of splinters that grow as columns at temperature warmer than $-10^{\circ} \mathrm{C}$ where the Hallett-Mossop process is active, and at colder temperatures where plates are favored subsequent diffusional growth occurs through capping plates. Such polycrystalline features are consistent with "the response of a column growing in a platelike growth regime" described by Bailey and Hallett (2009) in the context of cirrus crystals with well developed columnar forms developing polycrystalline plate or side-plane components while falling through plate growth regimes below. The Hallett-Mossop process also has been observationally associated with the generation of large number concentrations of pristine columnar crystals (e.g., Crosier et al., 2011). However, without a more careful analysis of abundance and contribution to total mass, the possibility of capped columns growing while falling in the vicinity of an updraft rather than rising through it (e.g., Heymsfield et al., 2002), or the dominance of some other process, cannot be ruled out.

Strengthening the updraft reduces the amount of time for diffusional growth, and the second mode is seen in Fig. 6 to be diminished relative to the baseline updraft profile. Weakening the updraft conversely provides more time for ice formed at warm temperatures to grow from vapor, with the second mode surpassing the modal $D_{\text {eq }}$ of the observational target. And while this mode develops a few grams per cubic meter of ice in the weak updraft at the expense of supercooled water, homogeneous freezing of drops still dominates the mass (seen in IWC profile) and numbers (seen in $N_{\mathrm{i}}$ profile) of ice particles, and thus their $\mathrm{MMD}_{\mathrm{eq}}$ is only modestly affected at cold temperatures aloft.

The second mode of the ice PSD has more than 3 times the total mass in the weak updraft relative to the baseline updraft, but the ascent time is only twice as long, and can directly account for only a factor of 2 , though there is a positive feedback in which more vapor deposition leads to greater ice surface area and thus more deposition. Additionally, fewer water drops in the weaker updrafts (see Sect. 4.3) provide less competition with the ice for vapor growth, since distributing the same LWC over a smaller number of water drops results in less total surface area available for condensation. 

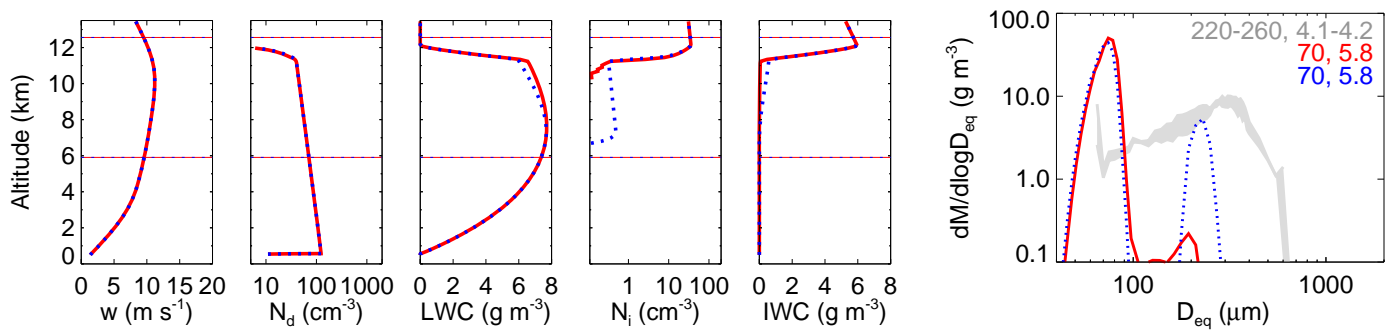

Figure 6. As in Fig. 4 for simulations that also include a pseudo-Hallett-Mossop source producing $1 \mathrm{std} \mathrm{cm}^{-3}$ splinters with baseline updraft strength scaled by factors of 0.5 (red solid line), 1.0 (blue dotted line, same as in Fig. 5), and 1.5 (green dashed line). Note that vertical scale for ice PSDs is logarithmic in preceding figures so that insubstantial larger mode is evident, but is linear hereafter.

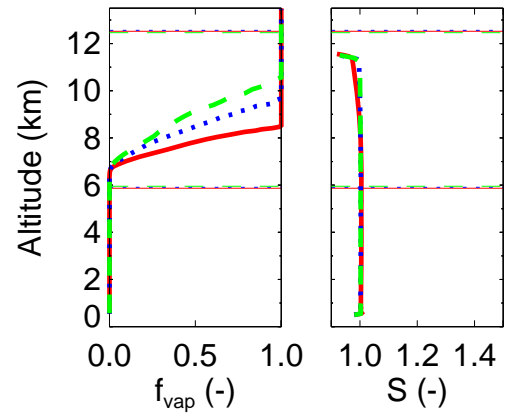

Figure 7. Vertical profiles of fractional hydrometeor diffusional growth occurring as vapor deposition on ice ( $f_{\text {vap}}$, in which zero corresponds to no depositional growth of ice and unity indicates that only ice is growing from vapor diffusion) and saturation vapor ratio with respect to liquid water $(S)$ for simulations in Fig. 6. Horizontal lines as in Fig. 4. Details provided in text.

Above $8 \mathrm{~km}$ altitude or so there is even less LWC to distribute, owing to a positive feedback in which greater depositional growth of ice results in less condensational growth of water drops, further diminishing competition from the drops. The resulting reduction in vapor competition with decreasing updraft strength is seen in Fig. 7 in terms of the fraction of hydrometeor diffusional growth occurring as vapor deposition on fluffy ice:

$f_{\text {vap }}=\max \left(g_{f}, 0\right) /\left[\max \left(g_{l}, 0\right)+\max \left(g_{f}, 0\right)\right]$,

where $g_{f}$ and $g_{l}$ are the respective vapor mass exchange rates with ice particles and water drops, in which we omit only the solute and curvature terms from the complete growth expressions used in the model (the $g$ terms are much like Eqs. 1 and 2 of Korolev, 2008). Thus, at an altitude of about $8 \mathrm{~km}$ there is effectively no competition for vapor from the water drops in the weak updraft, while in the baseline and strong updrafts condensation of water drops accounts for about half and three quarters of the diffusional vapor sink, respectively.

Hereafter, pseudo-Hallett-Mossop ice formation is included and heterogeneous IFN neglected by default, except for sensitivity to drop shattering considered further below.

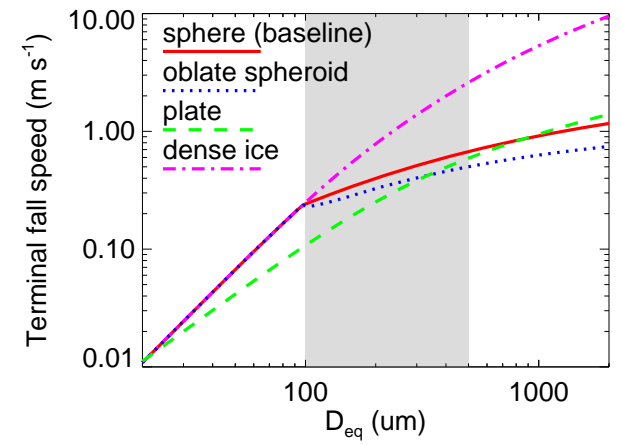

Figure 8. Terminal fall speeds for ice particles as a function of areaequivalent diameter at temperature $-20^{\circ} \mathrm{C}$ and pressure $350 \mathrm{hPa}$ for fluffy ice treated first as spheres (baseline treatment; red solid line), second as with the same mass-dimensional relation but as oblate spheroids (blue dotted line), and third as plates with a different mass-dimensional relationship (green dashed line), and for dense ice (dash-dotted magenta line, see Sect. 4.7). Filled area denotes predominant size range of ice mass in Airbus measurements. Details provided in text.

\subsection{Sedimentation}

Representing particle sedimentation in a parcel is problematic because in principle a parcel is zero-dimensional. However, it is implausible to ignore sedimentation during the duration of such deep ascent: the time for the parcel to climb from cloud base to $-40^{\circ} \mathrm{C}$ is just over $25 \mathrm{~min}$ for the baseline updraft and twice that for the weak updraft. Our approach is to treat the parcel as having a finite depth $\Delta z$ on the order of $1 \mathrm{~km}$ and calculate sedimentation as an implicit loss rate for hydrometeor concentration $\psi$ in each bin from $\mathrm{d} \psi / \mathrm{d} t=-\psi v_{\mathrm{f}} / \Delta z$, where $v_{\mathrm{f}}$ is the terminal fall speed for the hydrometeors in the bin. Baseline terminal fall speeds for hydrometeors are computed following Böhm (1989, 1992a, 1999 ) with a modification to the drag coefficient as described by Avramov et al. (2011).

For the parcel depth $\Delta z$, we consider the Sherwood et al. (2013) analysis of updraft thermals in CRM simulations of cumulus congestus driven by a surface heat source $80 \mathrm{~km}$ across. They report parcel sizes of about $1-2 \mathrm{~km}$ and derive 

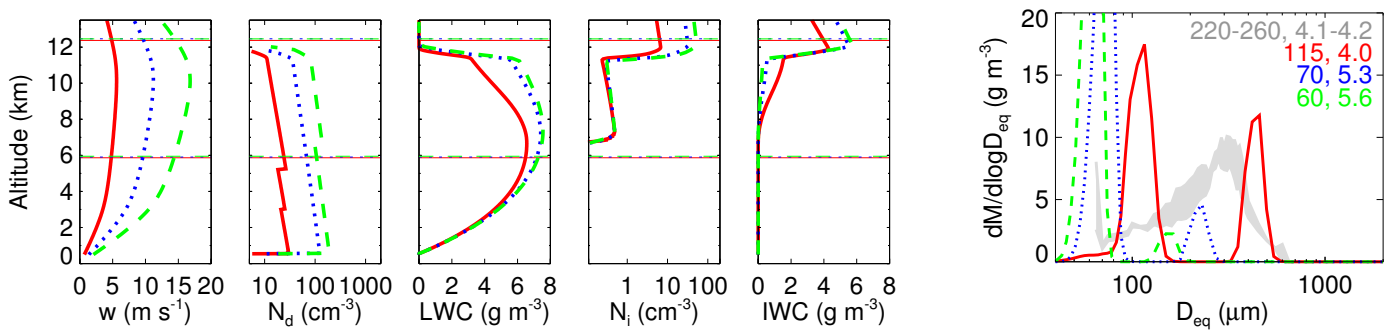

Figure 9. As in Fig. 6 for simulations that also allow sedimentation with parcel depth $\Delta z=1 \mathrm{~km}$.

a characteristic scale of about $2 \mathrm{~km}$, which they note is equivalent to the boundary-layer depth in their setup. Shallower boundary layers associated with maritime deep convection might be expected to result in smaller characteristic parcel sizes, so we consider values of $0.5,1$, and $2 \mathrm{~km}$ here. Note that the parcel concept is a convenient idealization and, as such, its dimension is not particularly well posed and does not obviously imply a representative updraft width that is comparable.

Terminal fall speeds for pristine ice particles are seen in Fig. 8 to be only about $0.1-0.6 \mathrm{~m} \mathrm{~s}^{-1}$ for particles across the mass mode $D_{\text {eq }}$ of about $100-500 \mu \mathrm{m}$ in the Airbus measurements, more than an order of magnitude smaller than updraft speeds in the baseline profile. (The discontinuity in slope near $D_{\text {eq }}=100 \mu \mathrm{m}$ corresponds to the transition from spheres with bulk density of ice to the Locatelli and Hobbs (1974) mass-dimensional relation described earlier.) Thus, the effect of sedimentation is seen in Fig. 9 to be modest for such particles, and at $-40{ }^{\circ} \mathrm{C}$ the IWC is reduced from $5.9 \mathrm{~g} \mathrm{~m}^{-3}$ in a simulation without sedimentation to $5.7,5.5$, and $5.1 \mathrm{~g} \mathrm{~m}^{-3}$ for $\Delta z=0.5,1$, and $2 \mathrm{~km}$, respectively, and no change in $\mathrm{MMD}_{\mathrm{eq}}(\Delta z$ sensitivity not shown). After considering additional microphysical processes we will return to the sensitivity of our results to the $\Delta z$ assumed, but in the meantime fix its value at $1 \mathrm{~km}$.

Weaker updrafts provide greater ascent time, which favors the source of condensate from diffusional growth as seen already, but also favors the removal of condensate by sedimentation. Thus, comparing Figs. 6 and 9, the greatest impact on IWC is seen for the weak updraft: at $-40{ }^{\circ} \mathrm{C}$ sedimentation reduces IWC by about $25 \%$ relative to the corresponding case without sedimentation. For the strong updraft, sedimentation reduces IWC by less than $2 \%$ relative to the corresponding case without sedimentation.

Hereafter, sedimentation is included in all simulations.

\subsection{Gravitational collection}

Hydrometeor growth from particle collisions is treated with the semi-implicit method of Jacobson et al. (1994) on the master time step of $1 \mathrm{~s}$. The collection efficiency is given by the product of collision and coalescence efficiencies per Eq. (6) of Ackerman et al. (1995); for collisions with ice par- ticles instead of "coalescence efficiency" we refer to "sticking efficiency". The gravitational collision kernel is computed for hydrometeors following Böhm (1992b, c, 1994, 1999). The formulation of Böhm (1994) is used for riming of columns or when the maximum dimension of the larger particle is at least 10 times greater than that of the smaller particle and the terminal fall speed Reynolds number of the smaller particle is less than unity. The coalescence efficiencies of Beard and Ochs (1995) for self-collection of water drops are combined with those of Beard and Ochs (1984) for accretion, with a lower limit of 0.6 in the size range between accretion and self-collection per Beard and Ochs (1995) and only using their expression for self-collection when the smaller particle diameter is greater than $200 \mu \mathrm{m}$. These coalescence efficiencies are blended with those of Low and List (1982a) following Seifert et al. (2005). Collision-induced breakup of water drops is based on Low and List (1982b), incorporating corrections from Valdez and Young (1985) and List et al. (1987), and as an explicit scheme is sub-stepped with a $0.05 \mathrm{~s}$ time step for stability. The sticking efficiency of collisions between water drops and ice particles is assumed to be unity, and drop freezing is treated as instantaneous. Collisions between ice particles are expected to be inefficient at the temperatures for which ice is present in these parcel simulations, and are neglected by default for our parcel simulations, but considered in sensitivity tests discussed in Sect. 4.8.

For simplicity, raindrops that freeze with equivalent spherical diameter larger than $200 \mu \mathrm{m}$ are treated as ice spheres with the same mass but with the bulk density of ice $\left(0.92 \mathrm{~g} \mathrm{~cm}^{-3}\right)$, referred to hereafter as dense ice to distinguish it from the fluffier ice properties that are consistent with agreement of Airbus PSD and IWC measurements, as discussed in Sect. 3 of Part 1. Raindrop freezing can occur either through IFN activation within a water drop or through coagulation of a drop with an ice crystal of lesser mass. Sufficiently heavy riming of a fluffy ice crystal is also assumed to contribute a fraction of mass to dense ice following the approach of Khain et al. (2004). Below a cutoff size of $200 \mu \mathrm{m}$ in maximum dimension, fluffy ice particles are assumed unable to collect water drops, following the treatment of collisions between plates and water drops by Khain et al. (2004). Various studies support the existence of such a threshold size that is habit-dependent, generally increasing with crystal branch- 

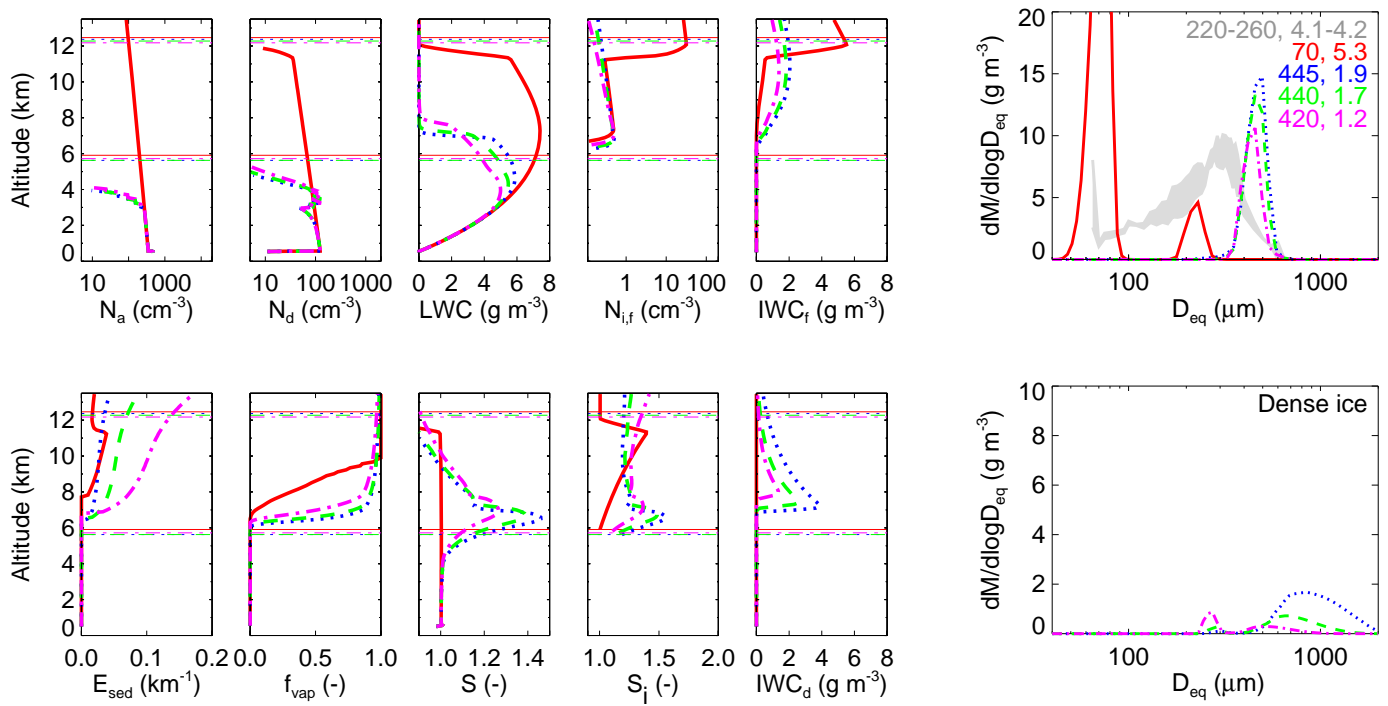

Figure 10. Top panels as in Fig. 9, except first panel is profile of total aerosol number concentration $\left(N_{\mathrm{a}}\right)$, for simulations with baseline updraft (red solid line) and additionally allowing gravitational collection and raindrop breakup with parcel depths $\Delta z$ of $2 \mathrm{~km}$ (blue dotted line), $1 \mathrm{~km}$ (green dashed line), and $500 \mathrm{~m}$ (magenta dash-dotted line). Ice in top panels refers to fluffy ice class only. Bottom panels are sedimentation efficiency for fluffy ice $\left(E_{\mathrm{sed}}\right)$, fractional hydrometeor diffusional growth occurring as vapor deposition on fluffy ice $\left(f_{\mathrm{vap}}\right)$, saturation ratios with respect to liquid water $(S)$ and ice $\left(S_{\mathrm{i}}\right.$, omitted for $\left.T>0{ }^{\circ} \mathrm{C}\right)$, dense ice water content (IWC $\left.\mathrm{d}\right)$, and dense ice PSD at $-40{ }^{\circ} \mathrm{C}$ (vertical scale half that for fluffy ice). Details provided in text.

ing, from about $50 \mu \mathrm{m}$ for capped columns to about $800 \mu \mathrm{m}$ for dendrites (Pruppacher and Klett, 1997, and references therein). In the absence of a size cutoff, low collision efficiencies on the order of $10 \%$ are otherwise computed, which could be reconcilable with threshold interpretations (Böhm, 1992c); we remove the cutoff as a sensitivity test that is discussed below.

Using the described treatment for gravitational collection and raindrop breakup leads to substantial loss of condensate mass and substantially larger ice particles, as seen in Fig. 10. Collision-coalescence dramatically reduces water drop concentrations below the melting level. There is a slight recovery from the initial dip in drop concentrations from the activation of aerosol around $3 \mathrm{~km}$ altitude, but by $4 \mathrm{~km}$ altitude the aerosol reservoir is depleted and droplet concentrations continue their decline. At about the same level sedimentation by larger raindrops is already desiccating the parcel (relative to the case without gravitational collection), at temperatures warmer than the Hallett-Mossop range. Subsequent ice production glaciates the parcel with $\Delta z=1 \mathrm{~km}$ by about $-8^{\circ} \mathrm{C}$ via collisions between ice splinters and raindrops. (We define glaciation throughout as the level at which $\mathrm{LWC}<0.1 \mathrm{~g} \mathrm{~m}^{-3}$.) While the number concentrations of fluffy ice particles are about the same with and without gravitational collection, their mass increases from diffusional growth much more appreciably in the presence of gravitational collection. This increased diffusional growth results from depletion of aerosols, droplets, and ultimately droplet surface area that otherwise (in the absence of gravitational collection) compete for vapor and limit the saturation ratio to little more than unity. The reduced competition for vapor is evident in the profile of $f_{\text {vap }}$, extended from Eq. (1) to also include competition from dense ice (in the denominator). In the absence of gravitational collection, the competition for vapor from condensation on water drops corresponds to greatly reduced values of $f_{\text {vap }}$ below about $10 \mathrm{~km}$ altitude. It is the lack of such competition that results in much greater fluffy IWC at altitudes below the homogeneous freezing level for parcels with gravitational acceleration. The lack of such competition is also seen in the fluffy ice PSDs aloft to result in a mode of vapor-grown ice that is substantially larger in terms of modal $D_{\text {eq }}$ as well as total mass (corresponding to the area under the curve in this PSD plotting convention). The lack of such vapor competition with supercooled water drops also corresponds to the lack of a smaller mode in the fluffy ice PSD aloft, which is attributable to homogeneous drop freezing in the absence of gravitational collection.

Gravitational collection is seen to result in substantial supersaturations at levels above which the aerosol and then droplets are depleted and below which there is sufficient surface area of ice, corresponding to altitudes just below the melting level to about $2 \mathrm{~km}$ above it. Notable supersaturations above the melting level are also realized in CRM simulations of deep convection, as discussed by Khain et al. (2012) and in references therein. As discussed below, entrainment of aerosol serves to reduce these supersaturations substantially. We note that breakup of raindrops contributes to the large supersaturations, as when that process is omitted, 
sedimentation depletes LWC faster, fewer raindrops collect smaller water drops, and more smaller water drops increase competition for water vapor, thereby reducing supersaturations (not shown).

The results are only mildly sensitive to an increase or decrease by a factor of 2 in the parcel depth $\Delta z$ used for sedimentation. Fluffy IWC at $-40^{\circ} \mathrm{C}$ is seen to change by less than $30 \%$ in response to changing $\Delta z$ by a factor of 2 either way, and $\mathrm{MMD}_{\mathrm{eq}}$ at that level barely responds to such variations in $\Delta z$. Perhaps the greatest impact seen above the melting level induced by an increase in $\Delta z$, corresponding to less efficient sedimentation, is an increase in dense IWC, the primary source of which is freezing of rain. Thus, less efficient sedimentation of rain yields greater dense IWC. Note that this dense ice, with a fall speed of about $5 \mathrm{~m} \mathrm{~s}^{-1}$ at a particle diameter of $1 \mathrm{~mm}$ as seen in Fig. 8, would not be expected to persist in anvil outflow, unlike the more slowly falling fluffy ice.

A so-called sedimentation efficiency, the inverse $e$-folding depth of fluffy IWC from sedimentation: $E_{\text {sed }}=P /(w \Delta z$ $\mathrm{IWC}_{\mathrm{f}}$ ), where $P$ is sedimentation flux of fluffy ice and $\mathrm{IWC}_{\mathrm{f}}$ the fluffy IWC, is seen to respectively increase and decrease by about a factor of 2 in response to decreasing and increasing $\Delta z$ at mid-levels, as expected from its formulation. The tendency of $E_{\text {sed }}$ to increase with height results not only from the increasing size of the fluffy ice particles but also from an increase in terminal fall speeds with decreasing air density. Computing instead a combined sedimentation efficiency for all hydrometeors (not shown), by vertically averaging liquidequivalent sedimentation fluxes $P$ and $(w \Delta z$ [LWC + IWC]) between cloud base and $-40{ }^{\circ} \mathrm{C}$, the resulting averages for $\Delta z$ of $0.5,1$, and $2 \mathrm{~km}$ are approximately $0.25,0.17$, and $0.11 \mathrm{~km}^{-1}$ for the baseline updraft strength. The magnitude of $E_{\text {sed }}$ would be a challenge to constrain from observations; we simply note that the vertical averages here for all hydrometeors are comparable to the constant value of $0.15 \mathrm{~km}^{-1}$ used by Kuang and Bretherton (2006). Their approach considered a convective plume with simplified cloud and precipitation microphysics, and their $E_{\text {sed }}$ value was empirically determined to produce reasonable results in the context of their other model assumptions. We assume $\Delta z=1 \mathrm{~km}$ for sedimentation hereafter.

Scaling up the pseudo-Hallett-Mossop source strength affects little other than the number concentration, size, and fluffy IWC. As seen in Fig. 11, a greater number of ice splinters results in smaller ice particles aloft, which would be expected if a fixed IWC were simply distributed over a greater number of ice particles. However, smaller ice particles fall more slowly and thus there is a modest sedimentation feedback in that somewhat more IWC is lofted when their numbers are so increased.

Note that if 350 ice splinters are produced from $1 \mathrm{mg}$ of accreted rime, as discussed above, a pseudo-Hallett-Mossop source of $2 \mathrm{std} \mathrm{cm}^{-3}$ would require riming nearly $3 \mathrm{~g} \mathrm{~m}^{-3}$ of supercooled water, equivalent to more than half the LWC at

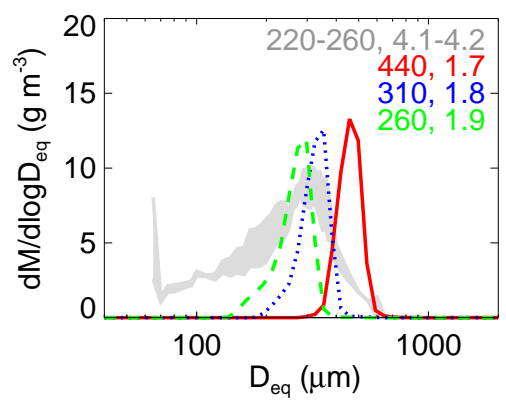

Figure 11. Particle size distributions of fluffy ice at $-40^{\circ} \mathrm{C}$ for simulations as in Fig. 10 with parcel depth $\Delta z=1 \mathrm{~km}$ and pseudoHallett-Mossop sources of 1 (red solid line), 2 (blue dotted line), and $3 \mathrm{std} \mathrm{cm}^{-3}$ (green dashed line).

$-5^{\circ} \mathrm{C}$ in the baseline updraft. A source of $3 \mathrm{std} \mathrm{cm}^{-3}$ would require riming all the supercooled water in the baseline updraft, which can be considered an upper limit on the pseudoHallett-Mossop source.

Given the overlap with the measured PSD mode at $D_{\mathrm{eq}} \approx$ $300 \mu \mathrm{m}$ for the simulation with a pseudo-Hallett-Mossop source of $2 \mathrm{std} \mathrm{cm}^{-3}$, we next vary the updraft strength using that pseudo-Hallett-Mossop source strength. As seen in Fig. 12, the baseline updraft best matches the observed ice PSD aloft.

In the case of the strong updraft, the parcel reaches the melting level before there is enough time for warm rain to deplete the parcel of liquid water. Glaciation is delayed until about $-21^{\circ} \mathrm{C}$, at which point frozen raindrops predominantly produce dense ice. Competition for vapor with water drops and then the dense ice, as evident in the reduced values of $f_{\text {vap }}$, reduces the diffusional growth of fluffy ice relative to the baseline and weak updrafts, resulting in substantially less fluffy IWC aloft and smaller $M_{M} D_{\text {eq }}$ for the strong updraft.

In Sect. 4.3 it was noted that the greater time of ascent in weaker updrafts provided for greater diffusional growth of fluffy ice particles. In the absence of gravitational collection, parcels were saturated with respect to liquid water and, not coincidentally, supercooled water was present all the way to the homogeneous freezing level, as seen in Figs. 6 and 7. In that limiting case, a longer ascent time provides a longer exposure to water saturation, and thus ascent time is a leading factor determining diffusional growth of ice. When gravitational collection is included, however, the limiting behavior of all parcels maintaining water saturation up to the homogeneous freezing level is no longer realized. Instead the updraft-strength dependence of fluffy ice diffusional growth relates primarily to competition for vapor. When gravitational collection is included, perhaps the most direct effect of greater ascent time in weaker updrafts is that it provides more time for the warm rain process to deplete LWC.

The fluffy ice PSD aloft is seen to be prominently bimodal for the weak updraft. Earlier times in the evolution of hydrometeor PSDs (not shown) reveal that the larger 

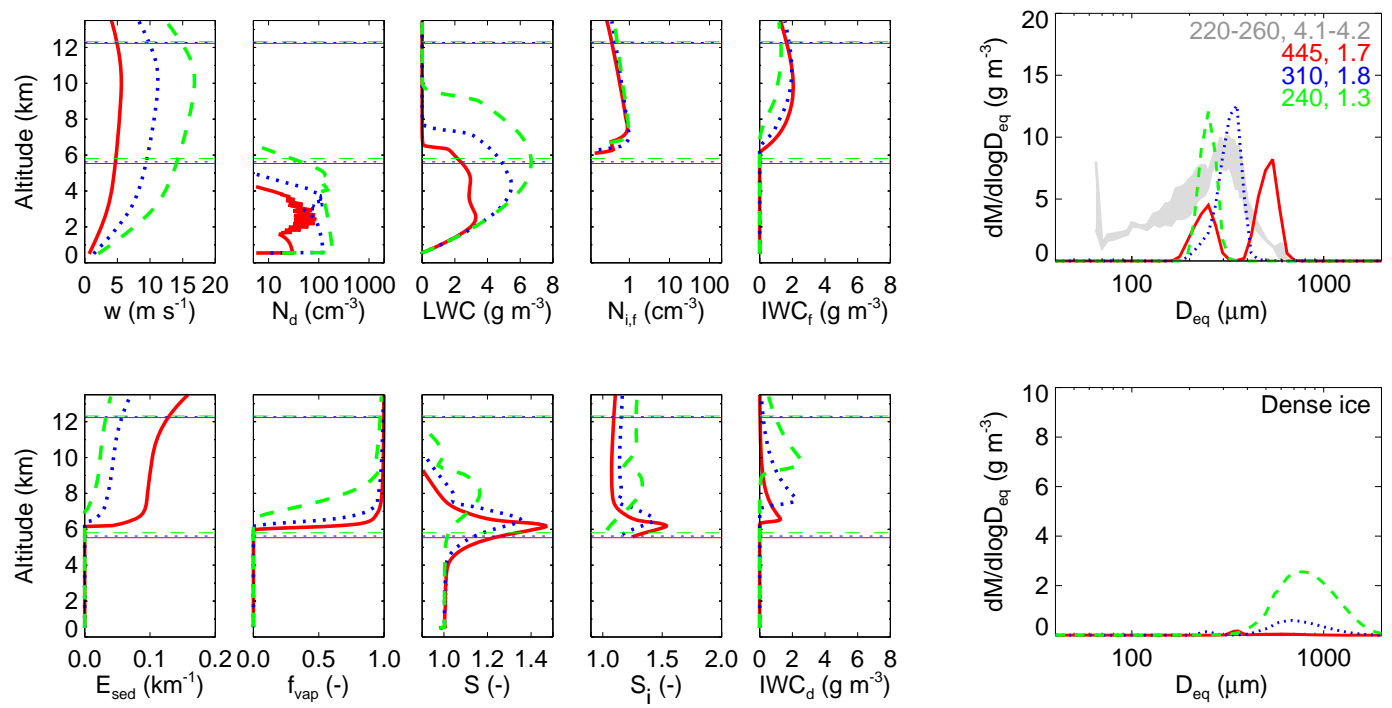

Figure 12. Panels and processes as in Fig. 10 with parcel depth $\Delta z=1 \mathrm{~km}$, pseudo-Hallett-Mossop source of $2 \mathrm{std}^{-3}$, and baseline updraft strength scaled by factors of 0.5 (red solid line), 1.0 (blue dotted line), and 1.5 (green dashed line).

mode forms on early Hallett-Mossop splinters, which form during supersaturated conditions in the weak updraft because collision-coalescence has time to sweep out all cloud droplets. The early splinters thus grow rapidly enough from vapor for the latent heat release to warm the parcel, delaying temperature-dependent production of further splinters until the parcel cools enough from adiabatic expansion. The smaller ice particle mode forms on those later splinters. While this production of a bimodal fluffy ice PSD makes sense in terms of the model physics, the treatment of HallettMossop ice production in the parcel model is rather contrived to overcome a lack of riming graupel particles entering the parcel from above. In nature or in a more realistic modeling framework there may well be other feedbacks that render such a bimodal feature an artifact of our parcel framework.

Although the focus of this study is the fluffy ice expected to persist in convective outflow, we note that the IWC of dense ice is seen in Fig. 12 to increase with updraft strength, from sedimentation of raindrops first and then of the dense ice that results from raindrops freezing.

As mentioned earlier, by default we assume that water drops are not collected by fluffy ice with a maximum dimension less than $200 \mu \mathrm{m}$. If we relax that assumption and instead use our computed collision efficiencies, the only notable change for the baseline updraft (not shown) is the parcel glaciates at about $-5^{\circ} \mathrm{C}$ instead of about $-8^{\circ} \mathrm{C}$ when we impose the size cutoff. The warmer glaciation corresponds to dense ice appearing about $1 \mathrm{~km}$ lower than in the baseline case, but fall speeds for raindrops and dense ice are comparable and there is little difference in results colder than about $-5^{\circ} \mathrm{C}$.

\subsection{Ice-ice collisions}

With gravitational collection included, if we allow collisions between fluffy ice particles with a sticking efficiency of 0.015 , the results (not shown) are indistinguishable from those in which such collisions are ignored. The value of 0.015 represents rather aggressive ice aggregation in 1-D column simulations described in Sect. 5 of Part 1 and in Sect. 4.10 below. While such a sticking efficiency results in substantial ice aggregation in the column simulations, the timescale over which collisions modify the ice PSD is about 2 orders of magnitude smaller in an updraft parcel framework; for stratiform precipitation the relevant speed for the transit timescale is set by ice particle terminal fall speeds on the order of $10 \mathrm{~cm} \mathrm{~s}^{-1}$ while in the parcel it is set by the updraft speed on the order of $10 \mathrm{~m} \mathrm{~s}^{-1}$.

If we instead follow Seifert and Beheng (2006) and use a temperature-dependent sticking efficiency of $\exp \left(0.09 T_{\mathrm{C}}\right)$ where $T_{\mathrm{C}}$ is air temperature in degrees Celsius, the resulting fluffy ice particles do become larger in the baseline updraft, with $\mathrm{MMD}_{\text {eq }}$ of 380 instead of $310 \mu \mathrm{m}$ at $-40^{\circ} \mathrm{C}$, but the fluffy IWC is unchanged (not shown). However, our 1D column simulations suggest that such a sticking efficiency formulation is implausibly aggressive, as discussed below in Sect. 4.10. Although there are reasons to expect aggregation to be more efficient at warmer temperatures, the observational basis for such an exponential dependence is unclear and current literature offers no alternative forms (KienastSjögren et al., 2013).

Given a null result in permitting collisions between fluffy ice particles with a plausible sticking efficiency in terms of our modeling frameworks, we neglect such collisions hereafter. 

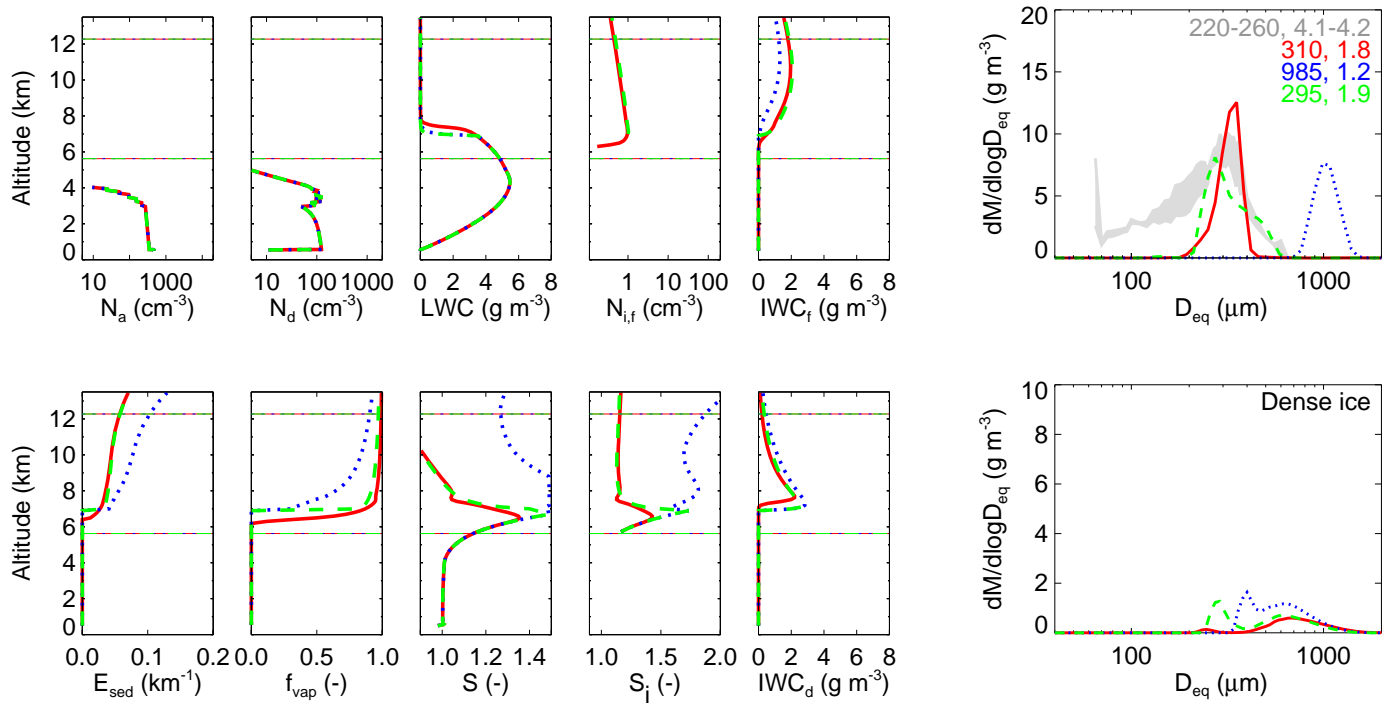

Figure 13. Panels and processes as in Fig. 10 for baseline updraft, with pseudo-Hallett-Mossop source of $2 \mathrm{std} \mathrm{cm}^{-3}$ (red solid line), and without pseudo-Hallett-Mossop source but with $1 \mathrm{std} \mathrm{cm}^{-3}$ of immersion-mode IFN and freezing-induced drop shattering with net multiplication factors of 5 (blue dotted line) and 50 (green dashed line). Details provided in text.

\subsection{Shattering of freezing drops}

We next consider the ice-multiplication process of some drops shattering during freezing. We follow Fridlind et al. (2007) and allow ice splinters to form when a water drop larger than $50 \mu \mathrm{m}$ in diameter collides with a smaller ice particle (with maximum dimension no greater than half the drop diameter) limited to temperatures between -5 and $-15^{\circ} \mathrm{C}$. We allow $N_{\text {sh }}$ splinters to form for $25 \%$ of such collisions, resulting in a net multiplication factor of $f_{\text {sh }}=0.25 N_{\text {sh }}$ (see Fridlind et al., 2007 and references therein for further description; note that for simplicity we adjust $f_{\text {sh }}$ so that the splinters formed fit evenly into one bin, which amounts to a miniscule adjustment for a grid with 150 bins). So as not to combine ice-multiplication processes but instead evaluate them separately, for the simulations with drop shattering we omit the pseudo-Hallett-Mossop source and instead revert to immersion freezing IFN as described in Sect. 4.4, at a concentration of $1 \mathrm{std} \mathrm{cm}{ }^{-3}$, or 100 times that of the DeMott et al. (2010) parameterization.

With a net multiplication factor of $f_{\mathrm{sh}}=5$ the freezinginduced drop shattering is seen in Fig. 13 to produce substantially more fluffy IWC than for simulations lacking it and a number of other processes, as seen in Fig. 5. However, the number concentration of fluffy ice particles is quite small (off scale in the figure) and the fluffy $\mathrm{MMD}_{\mathrm{eq}}$ aloft is nearly $1 \mathrm{~mm}$, substantially larger than the Airbus target. Increasing that net multiplication factor tenfold is seen to produce results closer to those with a pseudo-Hallett-Mossop source of $2 \mathrm{std} \mathrm{cm}^{-3}$ but without drop shattering. The fluffy ice PSD aloft is seen to be monomodal with $f_{\mathrm{sh}}=5$ but the development of a second mode is suggested by a shoulder for $f_{\mathrm{sh}}=50$. In the latter the mode of smaller particles corresponds to shattering of water drops grown from diffusional growth and the mode of larger particles to shattering of raindrops grown from collision-coalescence, and in subsequent diffusional growth the small ice particles do not catch up with the larger ones despite their faster relative growth. In contrast there is greater diffusional growth of ice particles with $f_{\mathrm{sh}}=5$ and fewer ice particles, and because of less ice surface area and greater supersaturations, the smaller do catch up with the larger particles, producing a single size mode by $-40^{\circ} \mathrm{C}$.

A net multiplication factor of $f_{\mathrm{sh}}=50$ is substantially greater than $f_{\text {sh }}<2$, which is the maximum value supported by published laboratory studies (cf. Fridlind et al., 2007). However, Lawson et al. (2015) recently combined microphysics measurements obtained within tropical cumulus clouds with a column model to derive an implied secondary ice particle production rate from drop shattering of $1000 \mathrm{mg}^{-1}$ of freezing drops ${ }^{1}$, which is about 3 times the Hallett-Mossop rate of $350 \mathrm{mg}^{-1}$ (as discussed in Sec. 4.5). Whereas their model is initialized with primary ice particles based on measurements, here primary ice particles are produced by IFN activation, for which we assume an abundance 100 times that of the DeMott et al. (2010) parameterization; to the extent that a secondary source such as Hallett-Mossop rime splintering is also active, the required IFN abundance could be reduced. Although a pseudo-Hallett-Mossop source is used in the remainder of this study for convenience, possible alternatives include abundant IFN combined with copious

\footnotetext{
${ }^{1}$ Note that on p. 2442 of Lawson et al. (2015), the optimized fragmentation factor should be $10^{9} \mathrm{~kg}^{-1}$ instead of $10^{-9} \mathrm{~kg}^{-1}$ as published (Paul Lawson, personal communication, 2015).
} 
drop shattering during freezing (with $f_{\text {sh }} \gg 2$ ) or some other multiplication process.

\subsection{Entrainment}

As discussed in Part 1, high IWC-low $Z_{\mathrm{e}}$ conditions are evidently prevalent in mature convection with developed stratiform precipitation characteristic of the Airbus measurements. So far we have ignored any mixing with environmental air, which we address next. We treat entrainment as a source term for each prognostic variable $\phi$ :

$\frac{\mathrm{d} \phi}{\mathrm{d} t}=\frac{\mathrm{d} z}{\mathrm{~d} t} \frac{\mathrm{d} \phi}{\mathrm{d} z}=w \epsilon\left(\phi_{\mathrm{env}}-\phi\right)$,

where $w$ is updraft speed, $\epsilon$ entrainment rate in units of reciprocal distance, and $\phi_{\text {env }}$ the environmental value of $\phi$ linearly interpolated to altitude $z$. The prognostic variables subject to entrainment are potential temperature, water vapor mixing ratio, and aerosol and hydrometeor concentrations in each size bin; heterogeneous IFN and potential pseudo-HallettMossop embryos are not subject to entrainment.

Being difficult at best to constrain through observation, we base our entrainment rates on CRM studies of deep tropical convection. In a study of the transition from shallow to deep maritime convection, Kuang and Bretherton (2006) reported vertical mass fluxes to be dominated by plumes with effective $\epsilon \lesssim 0.1-0.2 \mathrm{~km}^{-1}$ in their deep cumulus regime. In a study of more intense, continental convection during a monsoon break period, Del Genio and Wu (2010) reported the deepest ascent to be associated with $\epsilon \approx 0.2 \mathrm{~km}^{-1}$ in their control simulations, and tending toward larger values aloft, up to $0.5 \mathrm{~km}^{-1}$ in simulations with higher resolution. They suggest such strong entrainment rates might be reconcilable with those of Kuang and Bretherton (2006) by virtue of continental convection being more intense than maritime convection. Finally, Sherwood et al. (2013) consider convection driven by a surface heating source on the order of $100 \mathrm{~km}$ across and report a dominant $\epsilon \simeq 0.5 \mathrm{~km}^{-1}$ for the cumulus congestus regime they simulated in $3-\mathrm{D}$, while noting that for the strongest updrafts $\epsilon$ is reduced, falling to $0.2 \mathrm{~km}^{-1}$. Focused on a deep cumulus regime for maritime conditions, we use a vertically uniform $\epsilon=0.1 \mathrm{~km}^{-1}$ as our baseline, but consider greater $\epsilon$ in sensitivity tests.

Here we use steady-state results from 1-D column simulations of stratiform precipitation as described in Sect. 5 of Part 1 as a mixing environment for parcels. In these column simulations the Airbus measurement target serves as upper boundary condition for fluffy ice and the profiles of temperature and water vapor mixing ratio are from TWPICE soundings during the passage of the MCS on 23 January 2006. Instead of using the column model solution from Sect. 5 of Part 1 with 50 size bins, we use 150 bins to match our parcel configuration, and as in Sect. 5 of Part 1 compare our results with S-band profiles of $Z_{\mathrm{e}}$ and mean Doppler velocity (MDV) from TWP-ICE. (Note that there
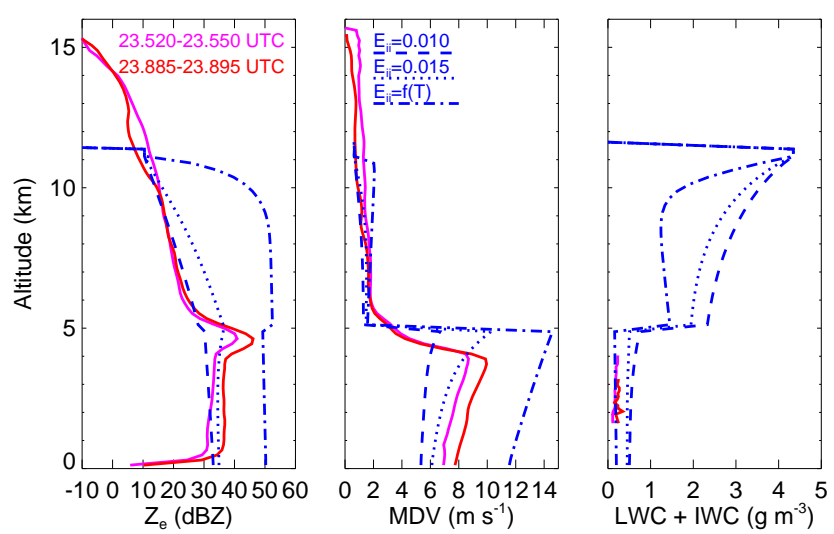

Figure 14. Profiles of Rayleigh-regime equivalent radar reflectivity factor $\left(Z_{\mathrm{e}}\right.$, left), mean Doppler velocity (MDV, center), and total hydrometeor condensed water content LWC + IWC (right) observed in stratiform region of mesoscale convective system during TWPICE through two different periods, labeled with times as decimal day of year UTC (magenta and red solid lines), and from steadystate column simulations using sticking efficiencies for collisions between fluffy ice particles of 0.01 (blue dashed lines), 0.015 (blue dotted lines), and $\exp \left(0.09 T_{\mathrm{C}}\right)$ with $T_{\mathrm{C}}$ air temperature in ${ }^{\circ} \mathrm{C}$ (blue dash-dotted line). Details provided in text.

are no mixed-phase particles in the model so there is no possibility of a bright band.) A uniform sticking efficiency of 0.01 is seen in Fig. 14 to reasonably match $Z_{\mathrm{e}}$ above the melting level. A uniform sticking efficiency of 0.015 is seen to better match observed $Z_{\mathrm{e}}$ below the melting level and MDV throughout the column, but produces excessive $Z_{\mathrm{e}}$ above. The temperature-dependent sticking efficiency from Lin et al. (1983) as adopted by Seifert and Beheng (2006), which yields a sticking efficiency already greater than 0.025 at $-40^{\circ} \mathrm{C}$, is seen in to result in excessive $Z_{\mathrm{e}}$ throughout the column and MDV below the melting level roughly $50 \%$ greater than observed. Primarily concerned with entrainment of ice above the melting level, we use column model results derived with a sticking efficiency of 0.01 for the entrainment environment.

Weak entrainment is seen in Fig. 15 to reduce LWC below the melting level, and stronger entrainment reduces LWC even more, owing to LWC in the entrained stratiform precipitation being less than $1 \mathrm{~g} \mathrm{~m}^{-3}$, which is less than that in the parcel above about $1 \mathrm{~km}$ altitude. Parcel simulations that entrain the same environment but without hydrometeors also reduce LWC comparably (not shown). Glaciation starts a bit lower in the ascent of the parcel with stronger entrainment, since ice reaches the melting level in the environment. However, both entraining parcels are seen to loft supercooled water higher than the non-entraining parcel: the non-entraining parcel glaciates near $-8{ }^{\circ} \mathrm{C}$ and the entraining parcels near $-18^{\circ} \mathrm{C}$. This lofting of supercooled water, which also occurs in parcels that entrain the environment with no hydrometeors (not shown), results from the rapid activation of droplets on 

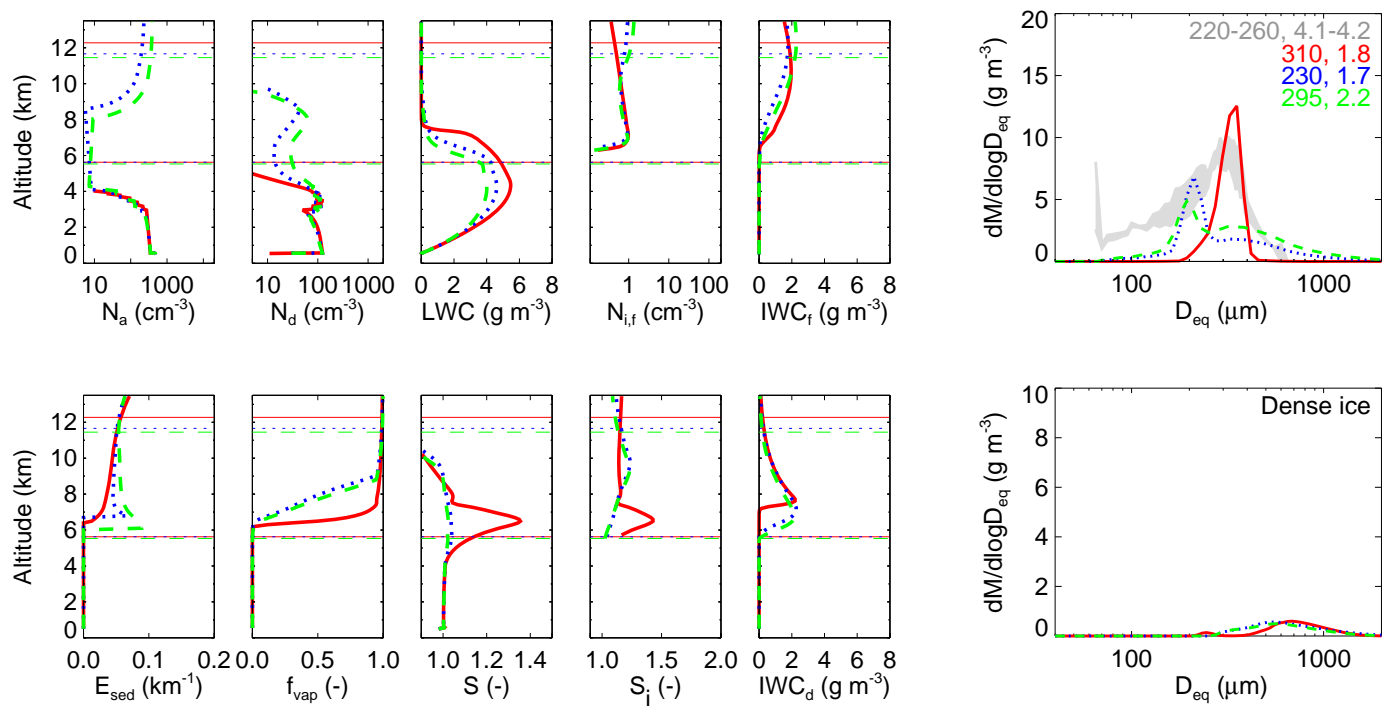

Figure 15. Processes and panels as in Fig. 12, except first panel is profile of total aerosol number concentration $\left(N_{\mathrm{a}}\right)$, for simulations with baseline updraft (red solid line) and additionally entraining environmental air from the steady-state column simulation with entrainment rates of 0.1 (blue dotted line) and $0.2 \mathrm{~km}^{-1}$ (green dashed line). Details provided in text.

any entrained aerosol above the melting level, seen in the enhanced water drop concentrations, which quenches the supersaturation that otherwise develops below the Hallett-Mossop level. Thus, although the entraining parcels entrain ice from the environment, fluffy IWC in the non-entraining parcel is greater in the first few kilometers above the melting level because of greater diffusional growth of splinters caused by the much greater supersaturation at those levels. At colder temperatures fluffy IWC in the parcel with stronger entrainment surpasses that of the non-entraining parcel primarily from entrainment of environmental ice, seen in Fig. 14 to exceed $2 \mathrm{~g} \mathrm{~m}^{-3}$ above the melting level and to increase upward.

The $-40^{\circ} \mathrm{C}$ level occurs at a lower level than for the nonentraining parcel, by about 700 and $900 \mathrm{~m}$ for parcels entraining at 0.1 and $0.2 \mathrm{~km}^{-1}$, primarily attributable to entrained air being colder than the parcel. The fluffy ice PSDs for the entraining parcels are seen to be comprised of (1) a broad mode corresponding to the entrained ice, populated at larger sizes in the column through aggregation, and (2) a narrow mode from diffusional growth of pseudo-Hallett-Mossop splinters. The narrow mode of fluffy ice diminishes in total mass and modal $D_{\text {eq }}$ as $\epsilon$ is increased; increasing $\epsilon$ to $0.5 \mathrm{~km}^{-1}$ is enough to effectively eliminate the narrow mode (not shown). The decreases in both the mass and modal $D_{\text {eq }}$ of the narrow mode result from a reduction in diffusional growth of pseudo-Hallett-Mossop splinters from decreased supersaturation and associated greater vapor competition in the first few kilometers above the melting level for the entraining parcels. Ultimately it is therefore entrainment of environmental aerosol that leads to the smaller modal $D_{\text {eq }}$ of the narrow mode in the fluffy ice PSD aloft, a point we shall revisit below.
For weakly entraining parcels the modal $D_{\text {eq }}$ of the narrow mode of the fluffy ice mass PSD aloft is seen in Fig. 16 to decrease with increasing updraft strength, attributable to increased competition with water drops and then dense ice, as evident in the profile of $f_{\text {vap }}$ and discussed in Sect. 4.7 for non-entraining parcels. The broad mode of entrained ice is largely unresponsive to changes in updraft strength, explained to first approximation by the entrainment source being independent of updraft speed: $\mathrm{d} \phi / \mathrm{d} z=\epsilon\left(\phi_{\mathrm{env}}-\phi\right)$. That is, the degree to which a stronger updraft in this framework entrains more rapidly is canceled by the shorter time over which the entrainment occurs. The response of entraining parcels to changes in updraft strength is insensitive to modest changes in entrainment, insofar as the response is comparable for parcels with twice the baseline entrainment rate (not shown).

For weakly entraining parcels, the modal $D_{\text {eq }}$ of the narrow mode in the fluffy ice mass PSD aloft is seen in Fig. 17 to decrease with increasing numbers of pseudo-Hallett-Mossop splinters, attributable to increased competition for vapor among ice particles. The greater fluffy IWC aloft is consistent with slower sedimentation for the smaller ice particles.

\subsection{Ice properties}

So far we have treated ice as spheres with a massdimensional relation from Locatelli and Hobbs (1974) for aggregates of unrimed radiating assemblages of plates, side planes, bullets, and columns (see Sect. 4.2). A slight variation is to use the same mass-dimensional relation but instead of spheres treat the particles as oblate spheroids, done by numerically inverting the dependence of randomly pro- 

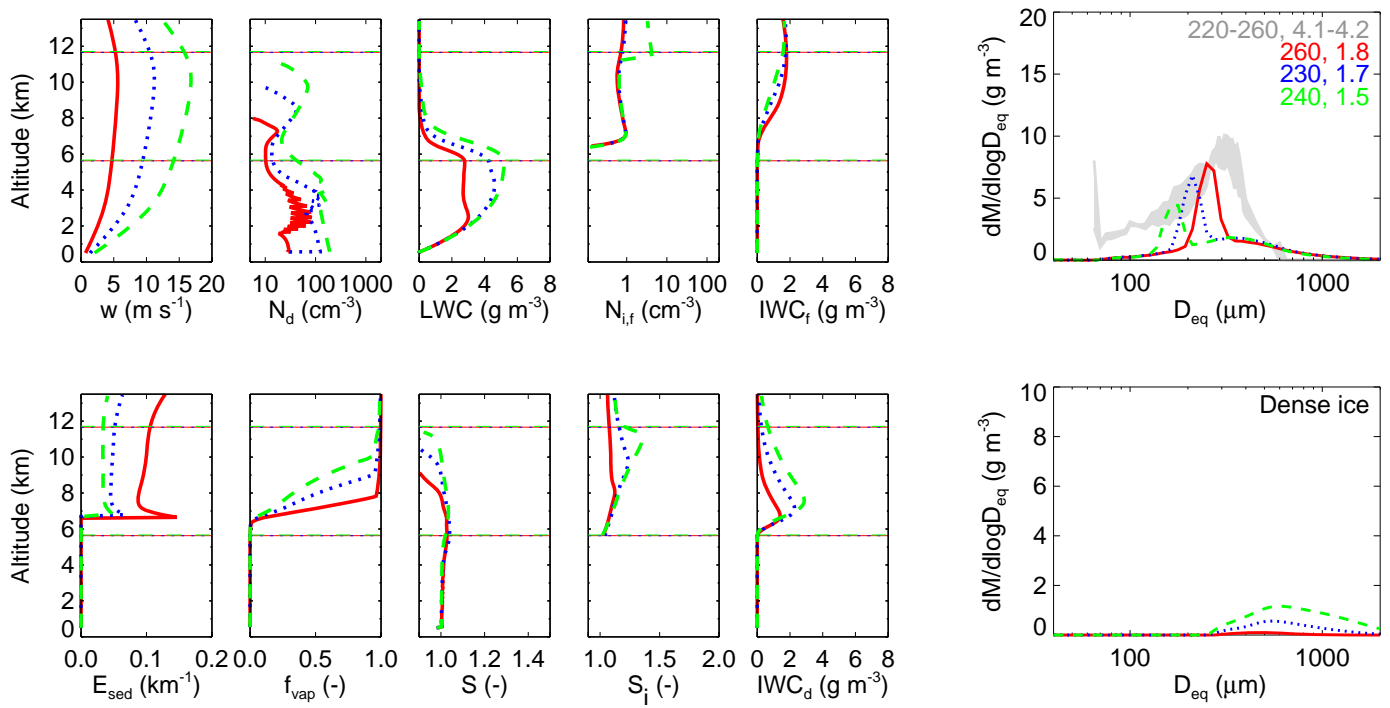

Figure 16. Processes and panels as in Fig. 15, for simulations with entrainment rate of $0.1 \mathrm{~km}^{-1}$ and baseline updraft strength scaled by factors of 0.5 (red solid line), 1.0 (blue dotted line), and 1.5 (green dashed line).

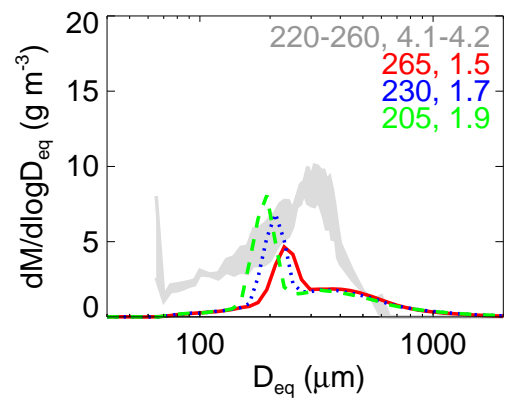

Figure 17. Particle size distributions of fluffy ice at $-40{ }^{\circ} \mathrm{C}$ for simulations as in Fig. 16 with baseline updraft and pseudo-HallettMossop sources of 1 (red solid line), 2 (blue dotted line), and $3 \mathrm{std} \mathrm{cm}^{-3}$ (green dashed line).

jected cross sectional area on spheroid volume to determine the dependence of particle aspect ratio on $D_{\text {eq. }}$. The particle geometries are then used in the capacitance shape factors for diffusional growth as well as for terminal fall speeds. For a given ice volume an oblate spheroid falling with its axis of rotation parallel to the flow falls slower than a sphere, as seen in Fig. 8. This reduction has very little impact on parcel simulations that include gravitational collection (not shown).

However, the mass-dimensional relation used for spheres and oblate spheroids corresponds to rather large densities for vapor-grown ice particles. As an alternative we treat fluffy ice particles with a maximum dimension greater than $15 \mu \mathrm{m}$ as hexagonal plates by adopting the area- and mass-dimensional relations of Mitchell and Arnott (1994) and treating them as spheres at smaller sizes. Terminal fall speeds are seen in Fig. 8 to be substantially reduced for $D_{\text {eq }}$ from tens to hundreds of micrometers. This reduction in fall speeds does im-

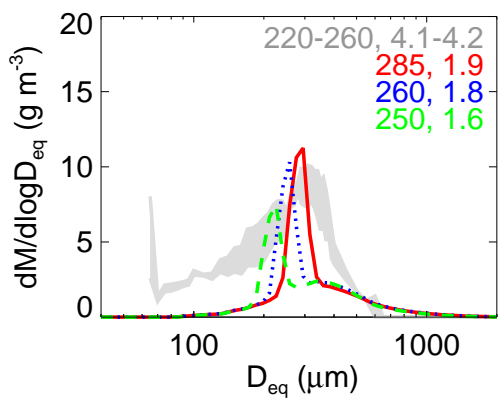

Figure 18. Fluffy ice size distributions at $-40{ }^{\circ} \mathrm{C}$ for simulations as in Fig. 16 but with fluffy ice treated as plates. Details provided in text.

pact our results, if subtly; although profiles are little affected (not shown) it is seen by comparing Figs. 16 and 18 that there is some effect on the fluffy ice PSDs aloft. The changes are principally attributable to particle geometry alone, in which $D_{\text {eq }}$ of such a plate is somewhat greater than for a fluffy sphere in our baseline treatment.

\subsection{Aerosol population}

A multiplicity of variations in aerosol populations are possible, including any of the parameters characterizing the initial multimodal size distribution in the parcel and assumed chemical composition, as well the vertical profile of aerosol entrained by the parcel. Here we merely decrease and increase initial aerosol number concentrations in all three modes by a factor of 25, in both the initial condition of the parcel and in the environment. These aerosol changes are seen in Fig. 19 to induce respective decreases and increases of less than a factor of 10 in cloud droplet number concentration $\left(N_{\mathrm{d}}\right)$ near cloud 

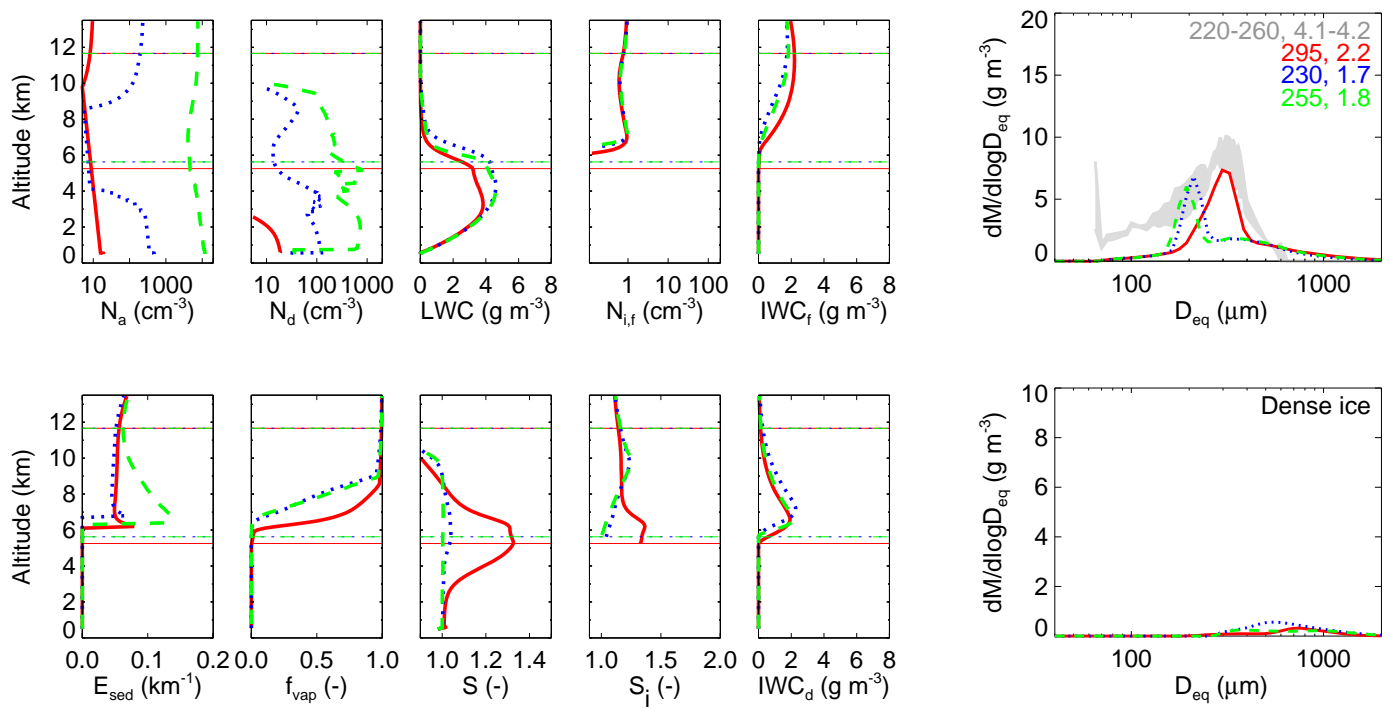

Figure 19. As in Fig. 16, except first panel is profile of total aerosol number concentration $\left(N_{\mathrm{a}}\right)$, for simulations with initial and entrained aerosol number concentrations scaled by factors of 1/25 (red solid line), 1 (blue dotted line), and 25 (green dashed line).

base. This less than linear response of $N_{\mathrm{d}}$ to changing aerosol number concentrations results from a negative feedback in which increasing $N_{\mathrm{d}}$ leads to increased total droplet surface area, which quenches peak supersaturations and thereby increases the size of the smallest aerosol activated near cloud base (e.g., Twomey et al., 1968; Abdul-Razzak et al., 1998). The effects of such changes in $N_{\mathrm{d}}$ on warm rain process are seen to be modest in entraining parcels. The parcel with access to the fewest aerosol particles is seen to become depleted in $N_{\mathrm{d}}$ well below the melting level, leading to greatly enhanced supersaturation and greater diffusional growth of ice splinters when they appear, which in turn results in a narrow mode of fluffy ice aloft that has more mass and a greater modal $D_{\text {eq. }}$.

Entrainment serves to buffer the response of the parcel to changes in aerosol number concentration, as non-entraining parcels respond in the same sense but with a greater magnitude of change to the fluffy ice PSD aloft, as seen in Fig. 20. In the parcel with access to the most aerosol particles, the soinhibited warm rain process barely affects the LWC profile below the melting level, which is thus nearly adiabatic (cf. Fig. 6). Fewer aerosol particles result in fewer droplets and less LWC, which both contribute to less competition for vapor by supercooled water, and thus fluffy IWC and the modal size of the dominant mode of fluffy ice PSD aloft increase with decreasing aerosol numbers. The bimodal PSD aloft for the non-entraining parcel with the fewest aerosol particles is similar to that discussed above for a non-entraining parcel in a weak updraft (see Sect. 4.7), in which lack of droplet surface area leads to enough diffusional growth on the first splinters to warm the parcel and delay further production of splinters, which come to comprise the smaller of the two modes aloft.

\subsection{Cloud base}

Reducing initial relative humidity of the parcel from 98 to $80 \%$ raises cloud base from about 600 to $1000 \mathrm{~m}$ (not shown). Since the updraft speed increases with altitude at those levels, such an increase in cloud base results in an increase in $N_{\mathrm{d}}$. The $N_{\mathrm{d}}$ increase is far less substantial than that induced by increasing aerosol numbers by a factor of 25 , and does not persist above the Hallett-Mossop zone, where entrained aerosol greatly influence $N_{\mathrm{d}}$. Thus, the changes induced aloft are minimal in response to a rather substantial increase in cloud-base altitude within this modeling framework.

\section{Discussion}

The Airbus flight-test measurements were obtained in a limited number of flights in maritime deep tropical convection with instrumentation having poorly characterized limitations and uncertainties (see Sect. 3 of Part 1). Results from the ongoing HAIC-HIWC field campaigns, with more robust and redundant instrumentation flown through a more extensive sample of deep tropical convection, should help to establish the extent to which the Airbus flight-test measurements are valid and not uncommon.

The predominant mass contribution of ice particles with sizes of a few hundred micrometers in the Airbus flights is generally consistent with the findings of Lawson et al. (2010) using different instrumentation and flying through deep tropical convection elsewhere in the tropics, though they cast their PSDs in terms of maximum particle dimension instead of $D_{\text {eq. }}$. In their conceptual model these ice particles form through heterogeneous ice nucleation at temper- 

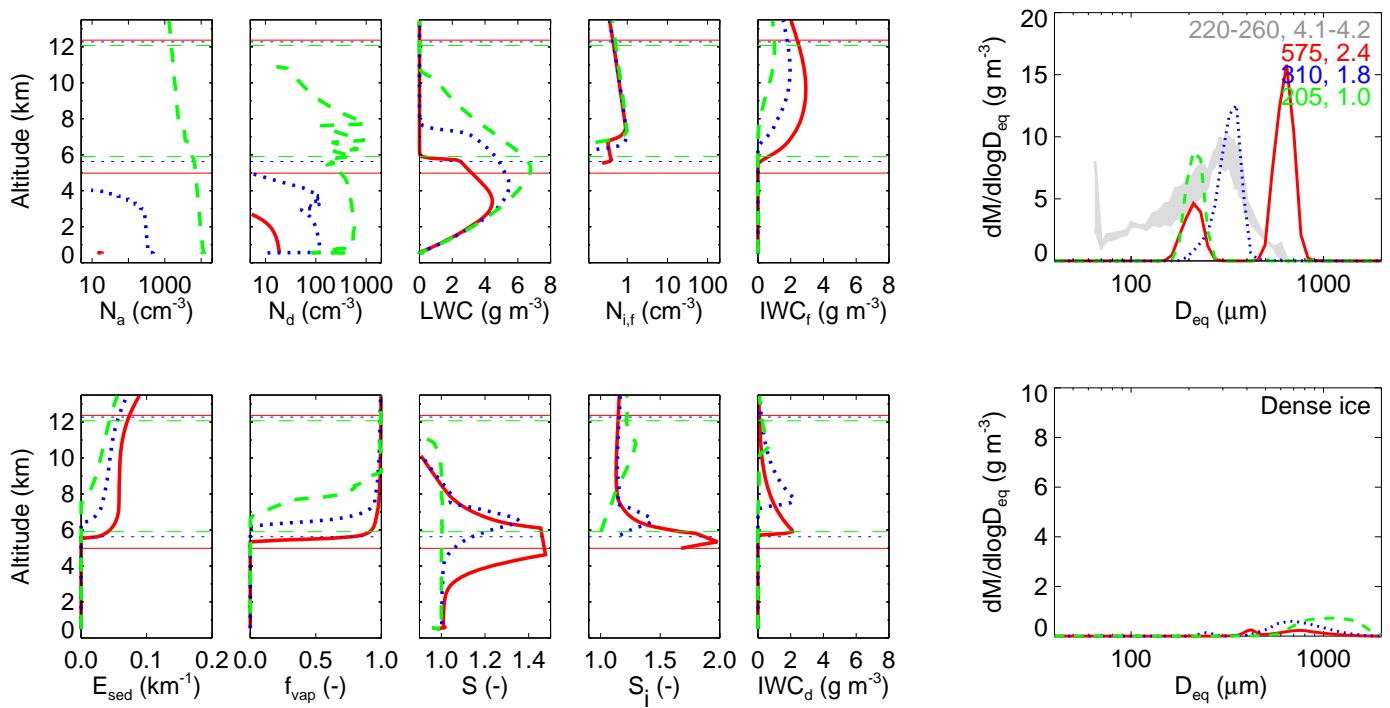

Figure 20. As in Fig. 19 but for non-entraining parcels.

atures colder than $-12{ }^{\circ} \mathrm{C}$ and then grow from vapor; however, the implied concentrations of IFN are not documented, and no mention is made of ice multiplication. In our parcel simulations we also find that ice formation at warm temperatures, around $-10^{\circ} \mathrm{C}$, is required to account for observed ice PSDs aloft, but we find that the required number concentrations of IFN are far in excess of measurements. With the absence of an ice-multiplication source, our results are consistent with a heterogeneous ice source at warm temperatures that is 5000 times greater than in the parameterization of DeMott et al. (2010). Another possibility in our parcel simulations is a sizable Hallett-Mossop ice splinter source, equivalent to riming about half of the available supercooled water, or alternatively a combination of abundant IFN and copious drop shattering during freezing. Notwithstanding, we note that an ice-multiplication source for maritime conditions might be consistent with ice residuals containing sea salt, sulfate, and organic constituents. For the TC4 and CRYSTALFACE campaigns respectively such constituents comprise 34 and $47 \%$ of residuals inferred as heterogeneous freezing nuclei (Cziczo et al., 2013, their Table S1). It is not inconceivable that better sampling of crystals larger than $75 \mu \mathrm{m}$ in diameter (Cziczo and Froyd, 2014) might alter such statistics.

Compared to the limitations of the measurements that comprise the observational target of this study, the shortcomings of our parcel framework present as great if not greater limitations. The parcel framework we consider is strictly for a deep convective updraft, but we compare its results with measurements thought to be more representative of a transitional regime between areas of convective and stratiform precipitation, as discussed in Sect. 2 of Part 1. Our parcel simulations that include gravitational collection include two ice classes, corresponding roughly to (1) less dense ice produced by ice nucleation and predominantly grown from va- por diffusion and (2) dense ice produced by freezing of raindrops and predominantly grown by riming. This latter class corresponds to graupel and hail, and we very crudely mimic a transition out of the convective cores by simply ignoring the dense ice when comparing with the measurements. Thus, any size sorting that might occur over the time between detrainment of convective air and its sampling in the transition region is missing from our parcel framework. However, Lawson et al. (2010) offer some evidence of similarity between updraft and outflow PSDs; measurements from the HAICHIWC campaigns should shed additional light.

There are other obvious simplifications in a parcel framework. A lack of graupel entering the parcel from above stymies a natural representation of the Hallett-Mossop process, which we emulate instead by introducing an adjustable number of ice splinters over the Hallett-Mossop temperature range, and our results are sensitive to the number of splinters produced, as seen in Figs. 11 and 17. It is noteworthy that the concentrations of splinters so produced would require riming a substantial fraction of the available supercooled water.

Our simplistic treatment of the Hallett-Mossop process bypasses any dependence on such parameters as LWC and duration spent in the Hallett-Mossop temperature range, both found to be critical to the overall production rate of splinters in a modeling study by Blyth and Latham (1997). Such dependence might contribute to feedbacks that explain the self-similarity of the ice PSDs measured by Airbus and discussed in Sect. 3 of Part 1. For instance, here we find that weaker updrafts favor greater mass and larger modal diameter of the dominant mass mode of fluffy ice aloft. While we find that an ice-multiplication source at warm temperatures is required to provide a narrow mode of fluffy ice aloft, increasing that multiplication source strength leads to smaller modal diameter for those ice particles. Thus, there may be an 
optimal range of updraft strengths that provide moderately sized, vapor-grown ice particles, in which the updrafts are weak enough to lose enough of their LWC via warm rain to not compete with vapor growth of ice, but not so slow that the duration spent in a temperature range conducive to ice multiplication generates so much small ice as to provide too much vapor competition to produce moderately sized ice particles through diffusional growth. Instead of trying to wedge the required assumptions into our parcel framework, which lacks graupel entering from above, we defer pursuit of such speculation to simulations in a more realistic modeling framework.

The representation of sedimentation in a parcel also suffers from a lack of hydrometeors entering the parcel from above, as the parcel only treats sedimentation losses but not sources. Furthermore, our treatment of sedimentation losses requires specification of a vertical length scale that we identify as parcel depth. A factor of 4 variation in that depth does not impact results substantially, as seen in results without rain in Fig. 10. Sensitivity of results to assumed parcel depth in entraining parcels (not shown) is muted relative to those without entrainment, as is sensitivity to other parameters.

Treatment of entrainment by the parcel requires profiles of not only entrainment rate but also the environment to be entrained. Doubling the assumed vertically uniform entrainment rate unsurprisingly results in solutions that more resemble the entrained environment, as seen in Fig. 15. We consider only one environment to entrain, namely the steadystate solution to a 1-D column simulation of stratiform precipitation. While such a sample of one is admittedly small, at least it is internally consistent with the observational target in terms of our model microphysics. We only consider one sounding of temperature and water vapor here, and limit our variety of initial thermodynamic conditions to varying the initial parcel relative humidity. We also use a single, multimodal aerosol profile from measurements during the TWPICE field campaign, and the only variation we consider is to simply scale it uniformly.

Another limitation is treating parcels as spatially homogeneous, which may lead to behaviors in non-entraining parcels that are questionable, such as warming of a rising parcel from rapid diffusional growth on early ice splinters in some special cases, shutting off production until further adiabatic cooling achieves Hallett-Mossop temperatures again, as seen in Figs. 10 and 20.

Further limitations are imposed by the specifics of a single microphysics model: how size distributions are discretized and the representation and numerical treatments of any number of processes.

We also bypass buoyancy-based computation of updraft speeds, simply imposing profiles of updraft speed using remote-sensing measurements in one monsoonal MCS. This approach misses possible influences of microphysics on dynamics, which could be considered an advantage in terms of simplifying interpretation. But the profile of updraft speed we use is subjected to the limitations of the retrieval method and the representativeness of the conditions sampled (see Varble et al., 2014). As a stab at exploring the sensitivity of our results to the specified updraft speed profile, we do consider variations by simply scaling the strength of our baseline updraft.

For all the simplifications of our parcel framework, the system is not wanting for complexity of behavior. In our pursuit of an explanation for a mode of ice particles between $D_{\text {eq }}$ of 200 and $300 \mu \mathrm{m}$ that dominate mass distributions measured in the Airbus flight tests, we have identified processes that merit further scrutiny in a more realistic modeling framework. Perhaps the greatest among them is ice multiplication at warm temperatures, whether through riming-induced splinter production or some other mechanism, such as drop shattering during freezing. The degree to which entrainment by updrafts suppresses the impact of new ice formation is also of interest. Perhaps more mundane but not lacking in influence are ice properties: mass-dimensional and area-dimensional relations, as well as particle geometry. These ice properties determine not only shape factors for diffusional growth, a detail treated in our model though overlooked in the analysis here, but also terminal fall speeds, likely to be even more important in convective outflow where particle lifetimes are greater.

\section{Conclusions}

As discussed in Part 1, in situ measurements were obtained during Airbus flight tests in maritime deep tropical convection outflow, characterized as a transitional regime between convective cores and areas of stratiform precipitation. Those measurements indicate that ice particle size distributions (PSDs) in conditions of high ice water content (IWC) and low equivalent radar reflectivity $\left(Z_{\mathrm{e}}\right)$, at temperatures where there is no evidence for supercooled water, are dominated in terms of mass by particles with area-equivalent diameters $\left(D_{\text {eq }}\right)$ between about 200 and $300 \mu \mathrm{m}$. Simulations run to steady state with a $1-\mathrm{D}$ column model using measured ice PSDs as an upper boundary condition suggest that the measurements are broadly consistent with Doppler radar observations of areas of stratiform precipitation during passage of a mesoscale convective system during the TWP-ICE field campaign.

The objective of this study is explanation of the notably narrow dominant mass mode of ice PSDs measured aloft (at around $-40^{\circ} \mathrm{C}$ ) based on a parcel modeling framework. While we do not derive a single explanation, our findings do provide a number of clues, as summarized here. (In simulations that include gravitational collection the model includes two ice classes, one that is predominantly vapor-grown and the focus of the following discussion.)

- Homogeneous freezing of water drops produces a mass mode in the ice PSD aloft at $D_{\text {eq }}<100 \mu \mathrm{m}$, generally consistent with an upturn in the measured ice PSDs at 
those sizes, but only in simulations that neglect hydrometeor gravitational collection; otherwise, water drops do not reach homogeneous freezing temperatures.

- A source of small ice particles at temperatures of about $-10^{\circ} \mathrm{C}$ or warmer provides sufficient time for diffusional growth to produce a narrow, substantial mass mode in the ice PSD aloft with $D_{\text {eq }}$ of a few hundred micrometers as in the measurements. Such a growth mode is consistent with an abundance of vapor-grown ice habits in the measurements, capped columns being commonly present in particle imagery.

- Entrainment of ice produces a broad mode aloft that is superposed with narrow mass mode of vapor-grown ice formed in the parcel at warmer temperatures. The mass contribution and modal $D_{\text {eq }}$ of the narrow mode diminish with increasing entrainment.

- The modal $D_{\text {eq }}$ of the vapor-grown ice mode aloft decreases with an increasing source of small ice particles, consistent with diffusional growth being limited by competition between particles.

- The total mass and modal $D_{\text {eq }}$ of the narrow mode of vapor-grown ice are greater for weaker updrafts, providing more time for warm rain to deplete a parcel of liquid water. Fewer drops and less liquid water (and later, reduced loading of dense ice) present less competition for the vapor-grown ice.

- The total mass and modal $D_{\text {eq }}$ of the dominant narrow mode in ice mass PSDs aloft diminish with increasing aerosol concentration, from a less efficient warm rain process that results in more competition for the vaporgrown ice.

Perhaps the most important result is that ice production at warm temperatures is required to produce vapor-grown ice of the sizes measured in convective outflow. Perhaps the most surprising result is that weaker updrafts lead to greater mass and larger modal diameter of the dominant mass mode of vapor-grown ice aloft, which is just the opposite of expectations regarding lofting of larger ice particles in stronger updrafts. Those expectations do apply to dense ice that are primarily the product of raindrop freezing. However, in terms of the less dense ice expected to persist in convective outflow, the slower ascent time in weaker updrafts allows the warm rain process to drive greater desiccation, which results in less competition (from water drops and dense ice) for diffusional growth of vapor-grown ice.

As discussed in Sect. 5, our contrived treatment of ice multiplication omits any dependence on the time spent in the temperature range conducive to ice multiplication. We speculate that such a dependence might select for an optimal range of updraft strengths: those that are weak enough to lose enough of the liquid water to the warm rain process to reduce competition with ice for vapor growth, but not so weak that the time spent at ice-multiplication temperatures produces so many ice splinters that vapor competition prevents their diffusional growth from reaching moderate sizes aloft.

As stated above, results from the ongoing HAIC-HIWC field campaigns are expected to shed light on the validity and generality of these Airbus measurements, and these parcel simulations can provide guidance and speculations for cloud-resolving model simulations targeting the upcoming measurements.

Acknowledgements. TWP-ICE soundings and S-band radar data were obtained from the Atmospheric Radiation Measurement (ARM) Program sponsored by the U.S. Department of Energy, Office of Science, Office of Biological and Environmental Research, Climate and Environmental Sciences Division. C-POL radar measurements and retrieval products were supplied by Peter May, Centre for Australian Weather and Climate Research, Australian Bureau of Meteorology. The authors thank Thomas Ratvasky and Renato Colantonio for logistical and programmatic assistance, and Jeanne Mason, Matthew Grzych, Alain Protat, and Alfons Schwarzenböck for valuable discussions and Airbus for providing their flight-test measurements. This work was supported by the NASA Aviation Safety Program's Atmospheric Environment Safety Technologies Project.

Edited by: T. Garrett

\section{References}

Abdul-Razzak, H., Ghan, S. J., and Rivera-Carpio, C.: A parameterization of aerosol activation: 1. Single aerosol type, J. Geophys. Res., 103, 6123-6131, 1998.

Ackerman, A. S., Toon, O. B., and Hobbs, P. V.: A model for particle microphysics, turbulent mixing, and radiative transfer in the stratocumulus-topped marine boundary layer and comparisons with measurements, J. Atmos. Sci., 52, 1204-1236, 1995.

Avramov, A., Ackerman, A. S., Fridlind, A. M., van Diedenhoven, B., Botta, G., Aydin, K., Verlinde, J., Korolev, A. V., Strapp, J. W., McFarquhar, G. M., Jackson, R., Brooks, S. D., Glen, A., and Wolde, M.: Toward ice formation closure in Arctic mixed-phase boundary layer clouds during ISDAC, J. Geophys. Res., 116, D00T08, doi:10.1029/2011JD015910, 2011.

Bailey, M. P. and Hallett, J.: A comprehensive habit diagram for atmospheric ice crystals: confirmation from the laboratory, AIRS II, and other field studies, J. Atmos. Sci., 66, 2888-2899, doi:10.1175/2009JAS2883.1, 2009.

Baumgardner, D., Brenguier, J.-L., Bucholtz, A., Coe, H., DeMott, P., Garrett, T. J., Gayet, J. F., Hermann, M., Heymsfield, A., Korolev, A., Krämer, M., Petzold, A., Strapp, W., Pilewskie, P., Taylor, J., Twohy, C., Wendisch, M., Bachalo, W., and Chuang, P.: Airborne instruments to measure atmospheric aerosol particles, clouds and radiation: a cook's tour of mature and emerging technology, Atmos. Res., 102, 10-29, doi:10.1016/j.atmosres.2011.06.021, 2011.

Beard, K. V. and Ochs, H. T.: Collection and coalescence efficiencies for accretion, J. Geophys. Res., 89, 7165-7169, 1984. 
Beard, K. V. and Ochs, H. T.: Collisions between small precipitation drops. Part II: Formulas for coalescence, temporary coalescence, and satellites, J. Atmos. Sci., 52, 3977-3996, 1995.

Blyth, A. M. and Latham, J.: A multi-thermal model of cumulus glaciation via the Hallett-Mossop process, Q. J. Roy. Meteor. Soc., 123, 1185-1198, 1997.

Böhm, H.: A general equation for the terminal fall speed of solid hydrometeors, J. Atmos. Sci., 46, 2419-2427, 1989.

Böhm, J. P.: A general hydrodynamic theory for mixed-phase microphysics. Part I: Drag and fall speed of hydrometeors, Atmos. Res., 27, 253-274, 1992a.

Böhm, J. P.: A general hydrodynamic theory for mixed-phase microphysics. Part II: Collision kernels for coalescence, Atmos. Res., 27, 275-290, 1992b.

Böhm, J. P.: A general hydrodynamic theory for mixed-phase microphysics. Part III: Riming and aggregation, Atmos. Res., 28, 103-123, 1992c.

Böhm, J. P.: Theoretical collision efficiencies for riming and aerosol impaction, Atmos. Res., 32, 171-187, 1994.

Böhm, J. P.: Revision and clarification of "A general hydrodynamic theory for mixed-phase microphysics", Atmos. Res., 52, 167176, 1999.

Bravin, M., Strapp, J. W., and Mason, J.: An investigation into location and convective lifecycle trends in an ice crystal icing engine database, Tech. rep., SAE Technical Paper 201501-2130, SAE International, Warrendale, Pennsylvania, USA, doi:10.4271/2015-01-2130, 2015.

Brown, P. R. A. and Francis, P. N.: Improved measurements of the ice water content in cirrus using a total-water probe, J. Atmos. Ocean. Tech., 12, 410-414, 1995.

Colella, P. and Woodward, P. R.: The piecewise parabolic method (PPM) for gas-dynamical simulations, J. Comput. Phys., 54, 174-201, 1984.

Connolly, P. J., Vaughan, G., May, P. T., Chemel, C., Allen, G., Choularton, T. W., Gallagher, M. W., Bower, K. N., Crosier, J., and Dearden, C.: Can aerosols influence deep tropical convection? Aerosol indirect effects in the Hector island thunderstorm, Q. J. Roy. Meteor. Soc., 139, 2190-2208, doi:10.1002/qj.2083, 2012.

Crosier, J., Bower, K. N., Choularton, T. W., Westbrook, C. D., Connolly, P. J., Cui, Z. Q., Crawford, I. P., Capes, G. L., Coe, H., Dorsey, J. R., Williams, P. I., Illingworth, A. J., Gallagher, M. W., and Blyth, A. M.: Observations of ice multiplication in a weakly convective cell embedded in supercooled mid-level stratus, Atmos. Chem. Phys., 11, 257-273, doi:10.5194/acp-11-257-2011, 2011.

Cziczo, D. J. and Froyd, K. D.: Sampling the composition of cirrus ice residuals, Atmos. Res., 142, 15-31, doi:10.1016/j.atmosres.2013.06.012, 2014.

Cziczo, D. J., Froyd, K. D., Hoose, C., Jensen, E. J., Diao, M., Zondlo, M. A., Smith, J. B., Twohy, C. H., and Murphy, D. M.: Clarifying the dominant sources and mechanisms of cirrus cloud formation, Science, 340, 1320-1324, doi:10.1126/science.1234145, 2013.

Del Genio, A. D. and Wu, J.: The role of entrainment in the diurnal cycle of continental convection, J. Climate, 23, 2722-2738, 2010.

DeMott, P. J., Prenni, A. J., Liu, X., Kreidenweis, S. M., Petters, M. D., Twohy, C. H., Richardson, M. S., Eidhammer, T., and Rogers, D. C.: Predicting global atmospheric ice nuclei distributions and their impacts on climate, P. Natl. Acad. Sci. USA, 107, 11217-11222, 2010.

Fridlind, A., Ackerman, A., McFarquhar, G., Zhang, G., Poellot, M., DeMott, P., Prenni, A., and Heymsfield, A.: Ice properties of single-layer stratocumulus during the Mixed-Phase Arctic Cloud Experiment: 2. Model results, J. Geophys. Res., 112, D24202, doi:10.1029/2007JD008646, 2007.

Fridlind, A. M., Ackerman, A. S., Chaboureau, J.-P., Fan, J., Grabowski, W. W., Hill, A. A., Jones, T. R., Khaiyer, M. M., Liu, G., Minnis, P., Morrison, H., Nguyen, L., Park, S., Petch, J. C., Pinty, J.-P., Schumacher, C., Shipway, B., Varble, A. C., Wu, X., Xie, S., and Zhang, M.: A comparison of TWP-ICE observational data with cloud-resolving model results, J. Geophys. Res., 117, D05204, doi:10.1029/2011JD016595, 2012.

Fridlind, A. M., Ackerman, A. S., Grandin, A., Dezitter, F., Weber, M., Strapp, J. W., Korolev, A. V., and Williams, C. R.: High ice water content at low radar reflectivity near deep convection - Part 1: Consistency of in situ and remote-sensing observations with stratiform rain column simulations, Atmos. Chem. Phys., 15, 11713-11728, doi:10.5194/acp-15-11713-2015, 2015.

Gayet, J.-F., Shcherbakov, V., Bugliaro, L., Protat, A., Delanoë, J., Pelon, J., and Garnier, A.: Microphysical properties and high ice water content in continental and oceanic mesoscale convective systems and potential implications for commercial aircraft at flight altitude, Atmos. Chem. Phys., 14, 899-912, doi:10.5194/acp-14-899-2014, 2014.

Grandin, A., Merle, J.-M., Weber, M., Strapp, J., Protat, A., and King, P.: AIRBUS flight tests in high total water content regions, in: 6th AIAA Atmospheric and Space Environments Conference, American Institute of Aeronautics and Astronautics, Reston, Virginia, USA, 16-20 June 2014, abstract number AIAA 2014-2753, doi:10.2514/6.2014-2753, 2014.

Grzych, M. L. and Mason, J. G.: Weather conditions associated with jet engine power loss and damage due to ingestion of ice particles: What we've learned through 2009, in: 14th Conference on Aviation, Range, and Aerospace Meteorology, 17-21 January 2010, Atlanta, Georgia, USA, abstract number 6.8, 2010.

Hallett, J. and Mossop, S.: Production of secondary ice particles during the riming process, Nature, 249, 26-28, 1974.

Heymsfield, A. J. and McFarquhar, G. M.: High albedos of cirrus in the tropical Pacific warm pool: Microphysical interpretations from CEPEX and from Kwajalein, Marshall islands, J. Atmos. Sci., 53, 2424-2451, 1996.

Heymsfield, A. J., Bansemer, A., Field, P., Durden, S., Stith, J., Dye, J., Hall, W., and Grainger, C.: Observations and parameterizations of particle size distributions in deep tropical cirrus and stratiform precipitating clouds: results from in situ observations in TRMM field campaigns, J. Atmos. Sci., 59, 1-35, 2002.

Heymsfield, G. M., Tian, L., Heymsfield, A. J., Li, L., and Guimond, S.: Characteristics of deep tropical and subtropical convection from nadir-viewing high-altitude airborne Doppler radar, J. Atmos. Sci., 67, 285-308, 2010.

Jacobson, M. Z., Turco, R. P., Jensen, E. J., and Toon, O. B.: Modeling coagulation among particles of different composition and size, Atmos. Environ., 28, 1327-1338, 1994.

Jackson, R. C. and McFarquhar, G. M.: An assessment of the impact of antishattering tips and artifact removal techniques on bulk cloud ice microphysical and optical properties measured 
by the 2D cloud probe, J. Atmos. Ocean. Tech., 32 2131-2144, doi:10.1175/JTECH-D-14-00018.1, 2014.

Jensen, E., Toon, O., Tabazadeh, A., Sachse, G., Anderson, B., Chan, K., Twohy, C., Gandrud, B., Aulenbach, S., Heymsfield, A., Hallett, J., and Gary, B.: Ice nucleation processes in upper tropospheric wave-clouds observed during SUCCESS, Geophys. Res. Lett., 25, 1363-1366, 1998.

Khain, A., Pokrovsky, A., Pinsky, M., Seifert, A., and Phillips, V.: Simulation of effects of atmospheric aerosols on deep turbulent convective clouds using a spectral microphysics mixed-phase cumulus cloud model. Part I: Model description and possible applications, J. Atmos. Sci., 61, 2963-2982, doi:10.1175/JAS-3350.1, 2004.

Khain, A. P., Benmoshe, N., and Pokrovsky, A.: Factors determining the impact of aerosols on surface precipitation from clouds: an attempt at classification, J. Atmos. Sci., 65, 17211748, doi:10.1175/2007JAS2515.1, 2008.

Khain, A. P., Phillips, V., Benmoshe, N., and Pokrovsky, A.: The role of small soluble aerosols in the microphysics of deep maritime clouds, J. Atmos. Sci., 69, 2787-2807, doi:10.1175/2011JAS3649.1, 2012.

Kienast-Sjögren, E., Spichtinger, P., and Gierens, K.: Formulation and test of an ice aggregation scheme for two-moment bulk microphysics schemes, Atmos. Chem. Phys., 13, 9021-9037, doi:10.5194/acp-13-9021-2013, 2013.

Korolev, A., Emery, E., and Creelman, K.: Modification and tests of particle probe tips to mitigate effects of ice shattering, J. Atmos. Ocean. Tech., 30, 690-708, doi:10.1175/JTECH-D-12-00142.1, 2013.

Korolev, A. V.: Rates of phase transformations in mixed-phase clouds, Q. J. Roy. Meteor. Soc., 134, 595-608, 2008.

Kuang, Z. and Bretherton, C. S.: A mass-flux scheme view of a high-resolution simulation of a transition from shallow to deep cumulus convection, J. Atmos. Sci., 63, 1895-1909, 2006.

Lawson, R. P., Angus, L. J., and Heymsfield, A. J.: Cloud particle measurements in thunderstorm anvils and possible weather threat to aviation, J. Aircraft, 35, 113-121, 1998.

Lawson, R. P., Jensen, E., Mitchell, D. L., Baker, B., Mo, Q., and Pilson, B.: Microphysical and radiative properties of tropical clouds investigated in TC4 and NAMMA, J. Geophys. Res., 115, D00J08, doi:10.1029/2009JD013017, 2010.

Lawson, R. P., Woods, S., and Morrison, H.: The microphysics of ice and precipitation development in tropical cumulus clouds, J. Atmos. Sci., 72, 2429-2445, doi:10.1175/JAS-D-14-0274.1, 2015.

Lin, Y.-L., Farley, R. D., and Orville, H. D.: Bulk parameterization of the snow field in a cloud model, J. Clim. Appl. Meteorol., 22, 1065-1092, 1983.

List, R., Donaldson, N., and Stewart, R.: Temporal evolution of drop spectra to collisional equilibrium in steady and pulsating rain, $\mathrm{J}$. Atmos. Sci., 44, 362-372, 1987.

Locatelli, J. D. and Hobbs, P. V.: Fall speeds and masses of solid precipitation particles, J. Geophys. Res., 79, 2185-2197, 1974.

Low, T. B. and List, R.: Collision, coalescence and breakup of raindrops. Part I: Experimentally established coalescence efficiencies and fragment size distributions in breakup, J. Atmos. Sci., 39, 1591-1606, 1982a.
Low, T. B. and List, R.: Collision, coalescence and breakup of raindrops. Part II: Parameterization of fragment size distribution, J. Atmos. Sci., 39, 1607-1618, 1982 b.

Mason, J. G. and Grzych, M.: The challenges identifying weather associated with jet engine ice crystal icing, Tech. rep., SAE Technical Paper 2011-38-0094, SAE International, Warrendale, Pennsylvania, USA, 2011.

Mason, J. G., Strapp, J. W., and Chow, P.: The ice particle threat to engines in flight, in: 44th AIAA Aerospace Sciences Meeting, Reno, Nevada, 9-12 January 2006, abstract number AIAA 2006206, 2006.

May, P. T., Mather, J. H., Vaughan, G., Jakob, C., McFarquhar, G. M., Bower, K. N., and Mace, G. G.: The tropical warm pool - international cloud experiment, B. Am. Meteorol. Soc., 89, 629-646, 2008.

McFarquhar, G. M. and Heymsfield, A. J.: Microphysical characteristics of three anvils sampled during the Central Equatorial Pacific Experiment, J. Atmos. Sci., 53, 2401-2423, 1996.

Mitchell, D. L. and Arnott, W. P.: A model predicting the evolution of ice particle size spectra and radiative properties of cirrus clouds. Part II: Dependence of absorption and extinction on ice crystal morphology, J. Atmos. Sci., 51, 817-832, 1994.

Mossop, S. C.: Production of secondary ice particles during the growth of graupel by riming, Q. J. Roy. Meteor. Soc., 102, 45-57, 1976.

Mossop, S. C. and Hallett, J.: Ice crystal concentration in cumulus clouds: Influence of the drop spectrum, Science, 186, 632-634, 1974.

Pruppacher, H. R. and Klett, J. D.: Microphysics of Clouds and Precipitation, 2nd edn., Kluwer Academic Publishers, Boston, USA, 1997.

Rangno, A. L. and Hobbs, P. V.: Microstructures and precipitation development in cumulus and small cumulonimbus clouds over the warm pool of the tropical Pacific Ocean, Q. J. Roy. Meteor. Soc., 131, 639-673, 2005.

Roques, S.: An airborne icing characterization probe: nephelometer prototype, Smart Mater. Struct., 16, 1784-1788, doi:10.1088/0964-1726/16/5/032, 2007.

Rosenfeld, D., Lohmann, U., Raga, G. B., O’Dowd, C. D., Kulmala, M., Fuzzi, S., Reissell, A., and Andreae, M. O.: Flood or drought: how do aerosols affect precipitation?, Science, 321, 1309-1313, doi:10.1126/science.1160606, 2008.

Rosenfeld, D., Yu, X., Liu, G., Xu, X., Zhu, Y., Yue, Z., Dai, J., Dong, Z., Dong, Y., and Peng, Y.: Glaciation temperatures of convective clouds ingesting desert dust, air pollution and smoke from forest fires, Geophys. Res. Lett., 38, L21804, doi:10.1029/2011GL049423, 2011.

Seifert, A. and Beheng, K. D.: A two-moment cloud microphysics parameterization for mixed-phase clouds. Part 1: Model description, Meteorol. Atmos. Phys., 92, 45-66, 2006.

Seifert, A., Khain, A., Blahak, U., and Beheng, K. D.: Possible effects of collisional breakup on mixed-phase deep convection simulated by a spectral (bin) cloud model, J. Atmos. Sci., 62, 19171931, 2005.

Sherwood, S. C., Hernández-Deckers, D., Colin, M., and Robinson, F.: Slippery thermals and the cumulus entrainment paradox, J. Atmos. Sci., 70, 2426-2442, 2013.

Stith, J. L., Avallone, L. M., Bansemer, A., Basarab, B., Dorsi, S. W., Fuchs, B., Lawson, R. P., Rogers, D. C., Rutledge, S., and 
Toohey, D. W.: Ice particles in the upper anvil regions of midlatitude continental thunderstorms: the case for frozen-drop aggregates, Atmos. Chem. Phys., 14, 1973-1985, doi:10.5194/acp-141973-2014, 2014.

Strapp, J., Chow, P., Maltby, M., Bezer, A., Korolev, A., Stromberg, I., and Hallett, J.: Cloud microphysical measurements in thunderstorm outflow regions during Allied/BAE 1997 flight trials, in: 37th AIAA Aerospace Sciences Meeting and Exhibit, American Institute of Aeronautics and Astronautics, Reno, Nevada, USA, 11-14 January 1999, abstract number AIAA 99048, 1999.

Strapp, J. W., MacLeod, J., and Lilie, L.: Calibration of ice water content in a wind tunnel/engine test cell facility, in: 15th Intl. Conf. on Clouds and Precipitation, Cancun, Mexico, 7-11 July 2008, abstract number P13.1, 2008.

Twomey, S., Howell, H. B., and Wojciechowski, T. A.: Comments on "Anomalous cloud lines", J. Atmos. Sci., 25, 333334, doi:10.1175/1520-0469(1968)025<0333:COCL>2.0.CO;2, 1968.

Valdez, M. P. and Young, K. C.: Number fluxes in equilibrium raindrop populations: a Markov chain analysis, J. Atmos. Sci., 42, 1024-1036, 1985.

van Diedenhoven, B., Fridlind, A. M., Ackerman, A. S., and Cairns, B.: Evaluation of hydrometeor phase and ice properties in cloud-resolving model simulations of tropical deep convection using radiance and polarization measurements, J. Atmos. Sci., 69, 3290-3314, 2012.
Varble, A., Zipser, E. J., Fridlind, A. M., Zhu, P., Ackerman, A. S., Chaboureau, J.-P., Collis, S., Fan, J., Hill, A., and Shipway, B.: Evaluation of cloud-resolving and limited area model intercomparison simulations using TWP-ICE observations. 1: Deep convective updraft properties, J. Geophys. Res., 119, 13891-13918, 2014.

Varble, A., Zipser, E. J., Fridlind, A. M., Zhu, P., Ackerman, A. S., Chaboureau, J.-P., Fan, J., Hill, A., Shipway, B., and Williams, C.: Evaluation of cloud-resolving and limited area model intercomparison simulations using TWP-ICE observations: 2. Precipitation microphysics, J. Geophys. Res., 119, 13919-13945, doi:10.1002/2013JD021371, 2015.

Yuan, T., Remer, L. A., Pickering, K. E., and Yu, H.: Observational evidence of aerosol enhancement of lightning activity and convective invigoration, Geophys. Res. Lett., 38, L04701, doi:10.1029/2010GL046052, 2011.

Zhu, P., Dudhia, J., Field, P. R., Wapler, K., Fridlind, A., Varble, A., Zipser, E., Petch, J., Chen, M., and Zhu, Z.: A Limited Area Model (LAM) intercomparison study of a TWP-ICE active monsoon mesocale convective event, J. Geophys. Res., 117, D11208, doi:10.1029/2011JD016447, 2012. 